\title{
COATED PELLETS FOR ORAL COLON DELIVERY
}

Luca Palugan, Matteo Cerea, Lucia Zema, Andrea Gazzaniga*, Alessandra Maroni

Università degli Studi di Milano, Dipartimento di Scienze Farmaceutiche, Sezione di

Tecnologia e Legislazione Farmaceutiche "Maria Edvige Sangalli", Via G. Colombo 71, 20133 Milan, Italy.

*Corresponding Author: andrea.gazzaniga@unimi.it, phone +39 02503 24654, telefax +390250324658. 


\section{Graphical abstract}

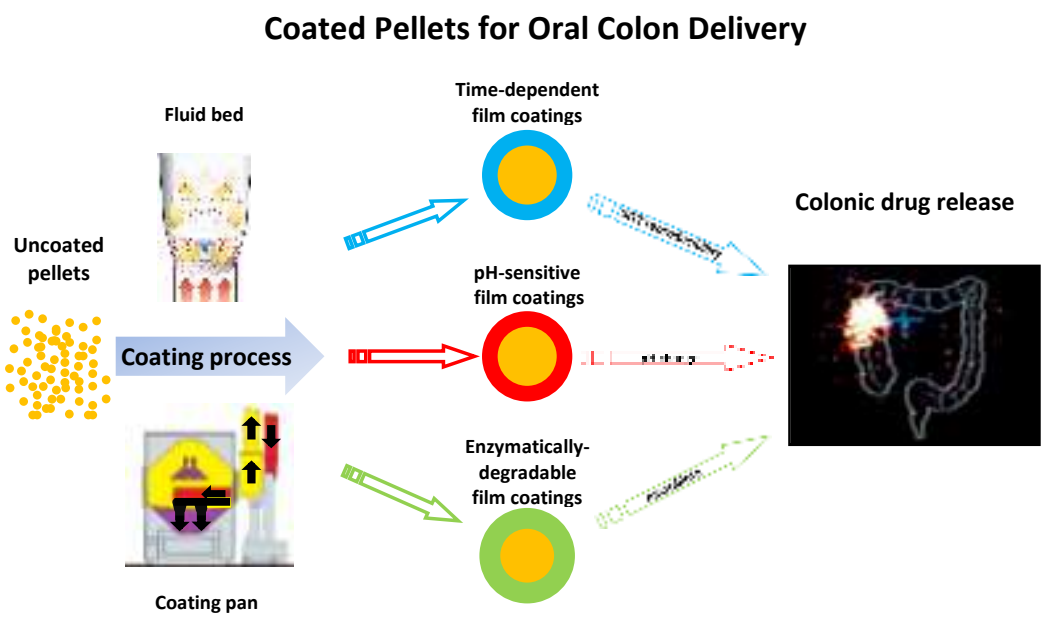




\begin{abstract}
Because of their spherical or pseudo-spherical shape, uniform size and smooth surface, pellets are of particular interest for use as cores in the manufacturing of coated oral delivery systems. When intended for colon delivery, pellet formulations may be provided with enzymatically-degradable, $\mathrm{pH}$-sensitive or time-controlled polymer coatings. While layers that are liable to microbial breakdown or $\mathrm{pH}$-dependent dissolution would enable targeted release as triggered by physiological characteristics of the environment where the drug is intended to be delivered, time-based coats possess an intrinsic ability to defer its liberation throughout the small intestinal transit of the dosage form irrespective of regional differences in terms of $\mathrm{pH}$, microbial population and other variables. Rupturable, erodible and permeable coats have been described for time-based colonic release. According to their formulation strategies, coated pellets that have been proposed for colon delivery are reviewed and discussed in the present article.
\end{abstract}

\title{
Keywords
}

Coating, Multiple-unit formulations, Oral colon delivery, Oral pulsatile release, Pellets.

\section{Introduction}

Pellets are multiple-unit pharmaceutical dosage forms, characterized by spherical or pseudo-spherical shape, smooth surface, dimensions generally comprised between 500 and $1500 \mu \mathrm{m}$, relatively high density and excellent flowability [1-3]. They are generally administered orally in hard-gelatin capsules or tablets, able to release, after intake, a large number of subunits, each containing a fraction of the total dose [4]. 
The production techniques for obtaining pellets are usually described as sizeenlargement processes. These include direct pelletization (by high-shear mixer or fluidized bed), hot melt extrusion (HME) or wet extrusion (extrusion/spheronization), layering of drug powders, suspensions or solutions onto inert cores (powder-, suspension- and solution-layering) and also the compaction of powders to small tablets, 1.5-2.5 $\mathrm{mm}$ in diameter, known as minitablets [1-3].

Pellets find specific application in the preparation of modified-release oral dosage forms when formulated as either matrix systems or coated reservoirs. Matrix systems are composed of an active ingredient closely dispersed within inert or swellable excipients able to control the drug release behaviour [5-7]. On the other hand, reservoir systems are designed as drug-containing cores, coated with one or more layers capable of defining the release kinetics. The release profiles are therefore determined by the thickness and the formulation characteristics of the coatings applied. The various techniques described in the literature for the application of coatings to pellets involve the formation of membranes produced by film-forming agents (mainly polymeric materials) delivered onto the surface of the cores as liquids or solids (Figures 1 and 2) $[8,9]$. When the coating systems are delivered as liquids, the film-forming agents are typically nebulized onto the surface of the cores as a solution or suspension in water or organic solvents. Since the cores are simultaneously heated by a flux of hot air, the liquid vehicle evaporates leaving a dry and solid film on their surface. In order to avoid or limit the use of solvents during the coating process, the film may be applied by spraying molten materials, which cool when in contact with the cores, or powders. Dry powder coating uses solid materials only, thus completely avoiding the need for liquids of any kind, while liquid-assisted powder coating requires liquid aids for promoting the 
adhesion of the powders onto the surface (liquid binder) or enabling the film formation process (liquid plasticizer) [10]. In this way, solid particles can eventually coalesce to form a continuous film. Coating processes for pellets can industrially be performed by fluid bed equipment (top, bottom or tangential spray) or coating pan (Figures 3 and 4). As regards fluid bed, the bottom-spray mode, which was purposely devised for the coating of small-unit substrates, is generally preferred, although tangential spray is also used at present [11]. In case the coating of pellets is performed by pan, non-perforated drums are employed with few modifications, such as the air flow pattern, with respect to when single-unit dosage forms are processed. However, examples of perforated pans suited for pellet coating are also available.

The use of pellets as cores offers many advantages in terms of technological characteristics and biopharmaceutical properties. From a technological point of view, it is possible to count on their regular shape, surface smoothness and adequate mechanical resistance that overall promote the application of coatings, besides the fact that pellet cores can be loaded with high drug doses [12-14]. On the other hand, the biopharmaceutical advantages are mainly related to the lower variability of the drug absorption profile that is expected when modified-release dosage forms are formulated as multiple units rather than as single units $[15,16]$. As a matter of fact, for single-unit systems the gastric emptying time is strongly influenced by the inter-digestive or digestive phase in which administration takes place. In contrast, multiple-unit dosage forms, consisting of numerous small subunits, may be able, depending on their size and density, to pass the stomach when the pylorus is contracted and would spread along the gut, thus possibly reducing the gastrontestinal transit variability and, particularly when the drug absorption rate is affected by the release site, the inter- and intra-subject 
differences in the absorption profiles. Another advantageous aspect of pellets is related to the subdivision of the dose in several subunits, which allows a distribution of the delivered dose on an extended surface area thus lowering the potential risk of mucosal injury caused by high local drug concentrations. Moreover, the subdivision of the dose reduces the possibility of dose-dumping should unpredictable failure of the releasecontrolling component occur.

In modified-release oral dosage forms, coating layers may be responsible for sustaining the drug liberation, modifying the relevant onset or preventing it from taking place in specific regions of the gastrointestinal tract. In the latter instance, the coatings are required to ensure that the delivery system conveys its drug load to the target site and that the contact between the drug compartment and the biological fluids is hindered until release.

In the case of colon delivery, the release of the active ingredient needs to be prevented during gastric residence as well as throughout small intestinal transit of the dosage form. The drug liberation would then occur based on environmental differences between the small and the large intestine, such as those encountered in the qualiquantitative composition of the microbiota and $\mathrm{pH}$ of the contents, or on transit times $[17,18]$.

Notably, the microbial population present in the colon, much more abundant than that residing in the small intestine, catalyzes an array of enzymatic reactions, many of which do not take place in the upper intestine [19-21]. Accordingly, various natural or synthetic polymers that are selectively degraded by colonic bacteria have been used for colon targeting either as carriers in prodrugs or as coating or bulking excipients in drug 
delivery systems. Such polymers generally bear glycoside or azo bonds that are susceptible to cleavage by the resident microbiota.

The $\mathrm{pH}$ of the fluids in the caecum and ascending colon is known to be slightly acidic because of bacterial fermentation activities that cause local accumulation of short-chain fatty acids $[22,23]$. Moving down to the transverse and descending branches of the colon, a neutral to weakly basic environment is re-established thanks to the progressive absorption of fermentation products. Therefore, polymers with $\mathrm{pH}-$ dependent solubility, soluble at $\mathrm{pH}$ above 5 (enteric polymers), have frequently been applied as relatively thick films intended to protect the core formulation during gastric residence and transit through the proximal small bowel, dissolving in the distal ileum or colon regions. Alternatively, polymers soluble at $\mathrm{pH}$ values below 5 have been proposed as coating agents to match the fall in $\mathrm{pH}$ that is commonly observed in the proximal colon [24]. In this case, however, an outer enteric film needs to be added in order to prevent the dissolution of the targeting layer while the dosage form is positioned in the stomach.

Lastly, unlike transit through the stomach, the mean transit time throughout the small intestine was reported to be fairly consistent $(3 \pm 1 \mathrm{~h})$ and poorly dependent on the size and density of the dosage forms as well as on the feeding state of the subjects, although significant acceleration was observed upon administration of nondisintegrating single units in a pre-feed state [25-29]. In the colon, solid substrates would generally reside for longer periods than in the small bowel because of less frequent propulsive peristaltic waves [30]. Therefore, systems intended to release the active ingredient after a sufficiently extended lag phase, which should cover their entire residence in the small intestine, have been exploited as time-dependent colon delivery 
platforms $[17,18,31,32]$. These require the application of an external enteric coating in order to circumvent the variability of gastric emptying time.

The colon represents an important release site for locally-acting molecules administered via the oral route. At present, long-term therapy of inflammatory bowel disease (IBD) mainly relies on targeted release of anti-inflammatory drugs $[33,34]$. Moreover, it has been suggested that local delivery of cycloxigenase-2 inhibitors and anti-cancer drugs would enable more tolerable chemopreventive and chemotherapeutic treatments for colorectal adenocarcinoma, respectively [35-37]. The liberation of $\beta$ lactamases into the large bowel could also provide a means of inactivating antibiotic residues that could harm the health state of the mucosa $[38,39]$. In addition, the colon has been investigated as an absorption site for biotechnological drugs intended for a systemic action, such as peptides and proteins, that often show poor stability and permeability in the GI tract [40-42]. Because of the limited protease concentration and of a greater susceptibility of the epithelium to permeation enhancement, the colon may indeed represent a more convenient release environment for these molecules.

In the following sections, pellet formulations provided with colon targeting coatings are described according to the inherent design strategies. In Tables 1-3, reviewed pelletbased delivery systems with enzymatically degradable, $\mathrm{pH}$-sensitive and time-controlled coats are listed, respectively, along with details on the relevant processing and composition.

\section{Pellets with enzymatically degradable coatings}


Naturally-occurring polysaccharides, such as pectin, chitosan, galactomannan and amylose, are generally preferred coating materials because of their safe use and administration as food additives.

\section{Pectin-based coatings}

Pectin is a heteropolysaccharide having a high $\alpha$-D-galacturonic acid content achievable from plant cell walls [43]. It is commercially available in low- and highmethoxylated forms (LM and HM) depending on the amount of etheric residues bestowing different reactivity, viscosity and solubility properties. Pectin has been employed for colon delivery as a matrix-forming or compression-coating agent [44]. In this case, it is generally admixed with insoluble polymers in order to achieve a more effective protection for the drug core.

A pectin/ethylcellulose (EC) mixture was applied to pellets containing either paracetamol or 5-aminosalicylic acid (5-ASA) for the treatment of IBD $[45,46]$. Different ratios between pectin and EC were used, and theoretical weight gains from 12 to $55 \%$ were reached. Enhanced barrier properties of the coating were observed in simulated small intestinal fluid at $\mathrm{pH} 7.4$ when an initial acid phase of the test (30 min or $2 \mathrm{~h}$ at $\mathrm{pH} 1.4$ ) was performed, which probably led to inter-chain hydrogen bonding of unionized carboxyl groups. The initial exposure to acidic $\mathrm{pH}$ also improved the susceptibility of the gel to the hydrolytic action of pectinases when simulated caecal fluid was employed, as shown by an increased release rate. The coating level and amount of pectin had an opposite influence on the rate of drug release in all test fluids. A general lack of in vivo-in vitro correlation was found: beads showing premature drug release in vitro could successfully deliver the drug to the colon. 
Pectin/EC mixtures with different weight ratios were also used to coat pellets containing 5-fluorouracil (5-FU) for the local chemotherapy of colorectal adenocarcinoma [47-49]. An increased in vitro release rate was noticed when the pellets were tested in the presence of rat caecal contents. This was confirmed by observing photomicrographs taken after incubation of the pellets in an enzyme-containing vs. enzyme-free fluid, and after recovery from the caecum and the colon of rats as compared with the stomach and the small intestine. Pellets coated up to a $30 \%$ weight gain showed, with respect to uncoated ones, a delayed $t_{\max }$, lower $\mathrm{C}_{\max }$ and longer mean residence time (MRT) that would be beneficial to the treatment of colorectal cancer. Besides, a correlation was found between in vitro data obtained from tests carried out in simulated colonic fluid and 5-FU plasma concentrations of fasting dogs. More recently, a powder mixture of pectin and EC (3:8) was added to pectin-based extrusionspheronization pellets containing 5-FU [50]. The pellets and the powder were conveyed inside hard-gelatin capsules. This formulation was designed to yield in vivo coating of the pellet surface upon wetting and swelling of the hydrophilic polymer.

With the aim of strengthening the barrier properties of pectin films, the addition of Eudragit ${ }^{\circledR} \mathrm{NE}$ or Eudragit RS was also attempted and compared with that of EC (i.e., Surelease Clear or Aquacoat ECD 30) [51]. Surprisingly, theophylline pellets coated with all the above-mentioned mixtures showed a decreased release rate when pectinolytic enzymes, expected to aid the formation of pores in the coat, were added to the test medium (acetate phosphate buffer $\mathrm{pH}$ 6), which was interpreted by a possible rearrangement of non-degradable polymer chains following pectin degradation. To overcome this issue, the use of polyelectrolyte complexes of pectin with an insoluble and non-enzymatically degradable polycation, Eudragit RL, was proposed so that water- 
filled channel could be maintained after enzymatic attack and, consequently, soluble drug molecules could be released at enhanced rate in the enzyme-rich target region [52].

Chitosan, a high molecular weight polysaccharide positively charged at acidic $\mathrm{pH}$, could form biodegradable polyelectrolyte complexes with pectin and also impart mucoadhesion properties to the films [53]. Theophylline pellets were thus coated with pectin LM/chitosan complexes mixed with Eudragit RS in percentages of 5-20\% on the dry polymethacrylate [54]. Evaluated in $\mathrm{HCl} 0.1 \mathrm{~N}(2 \mathrm{~h}), \mathrm{pH} 7.4$ phosphate buffer ( $3 \mathrm{~h})$ and $\mathrm{pH} 6.0$ simulated colonic fluid containing pectinolytic enzymes $(5 \mathrm{~h})$, the performance of formulations with a high pectin/chitosan content and weight gain of $20 \%$ was considered potentially appropriate. Moreover, riboflavin pellets, containing calcium acetate (10\%) as a complexing agent, underwent immersion in a pectin LM aqueous solution and then in a calcium chloride or chitosan one to obtain a coat formed from calcium pectinate or calcium pectinate/chitosan polyelectrolyte complexes $[55,56]$. The coat containing chitosan was able to hinder the release of the active ingredient in an enzyme-free $\mathrm{pH} 6.8$ fluid. Replacing pectin with alginate led to a further improvement of the coat performance.

Pectin was also employed in admixture with high-viscosity hydroxypropylmethylcellulose (HPMC) [57]. Pellets containing 5-ASA and calcium pectinate were coated with pectin and Methocel K4M (4:1, w/w) up to a weight gain of $12 \%$, and with EC externally (10\% weight gain). The swelling of the hydrophilic coating in the small intestine would cause the EC film to break up and allow the digestion of pectin by colonic enzymes thus speeding up the drug liberation at the target site. In order to improve the site-selectivity of release, an outer Eudragit L coating was applied (30\% weight gain). A higher-viscosity grade of HPMC (Methocel ${ }^{\circledR}$ K100M) 
was mixed with pectin in various weight ratios to coat curcumin pellets [58]. The formulation with a 3:1 HPMC/pectin ratio withstood $3 \mathrm{~h}$ of testing in acidic fluids and started to release when the $\mathrm{pH}$ of the test medium was shifted from 3 to 7.2. Afterwards, the drug liberation turned out to be controlled in terms of rate. The system, tested in rabbits, showed drug plasma concentrations increasing after 2-3 h until a peak at approximately $5 \mathrm{~h}$.

\section{Chitosan-based coatings}

Chitosan was frequently employed as the sole microbially-degradable excipient in colon delivery systems, generally mixed with insoluble polymers [59]. For instance, paracetamol-layered pellets were coated with a formulation containing chitosan and Eudragit RS (2:1, w/w) [60]. An outer enteric coating was added to prevent chitosan from dissolving at acidic $\mathrm{pH}$. These pellets were tested in a sequence of dissolution media: $\mathrm{pH} 1.2$ fluid, $\mathrm{pH} 7.4$ phosphate buffer and, finally, $\mathrm{pH} 4.0$ acetate buffer to simulate the inflamed colonic environment. In the latter medium, chitosan easily dissolved and the drug was released. Due to the lack of enzymes, however, the effect of microbial breakdown was could not be studied. This was assessed by exposing the pellets to either fresh or thermally-inactivated rat caecal contents and then observing their surface with the aid of SEM photomicrographs.

Prednisolone pellets were in turn coated with $i$ ) Eudragit RS and Eudragit RL (80:20 weight ratio), ii) chitosan, Eudragit RS, Eudragit RL and a weak organic acid and iii) Eudragit L [61]. Among various organic acids tested, the use of succinic acid provided the fastest rate of release in $\mathrm{pH} 4.0$ acetate buffer, which was ascribed to electrostatic interactions with chitosan and the polymethacrylates. As compared with pellets coated with a Eudragit RS/Eudragit RL mixture only, three-layered ones exhibited enhanced 
drug release when tested in $\mathrm{pH} 6.0$ phosphate buffer with $\beta$-glucosidase or in $\mathrm{pH} 4.0$ acetate buffer without enzymes. Moreover, an in vivo study in rats showed that the presence of the three-layer coating was associated with only slightly delayed, considerably slowed down and unexpectedly greater absorption with respect to a single Eudragit L coat.

Alternatively, chitosan was mixed with polyvinyl acetate (PVA) to give colon targeting films. Pellets containing 5-ASA were coated with such mixtures up to a 15 or $25 \%$ weight gain [62]. In vitro testing demonstrated that the release of 5-ASA increased when caecal enzymes or $\beta$-glucosidase were present. Tested in rats, the PVA/chitosancoated pellets yielded lower plasma levels and higher concentrations of the drug in colonic homogenates than in gastric and small intestinal ones with respect to an uncoated formulation. Moreover, they showed higher efficacy against mucosal damage and inflammation. In a different instance, extrusion-spheronization 5-ASA pellets were coated with aqueous dispersions of chitosan and EC [63]. The percentage of the biodegradable polymer and thickness of the applied layer were critical to the performance. With $8 \%$ of chitosan and a $60 \%$ weight gain, the drug liberation was quite slow at $\mathrm{pH} 6.8$, being less than $40 \%$ of the drug being delivered over $28 \mathrm{~h}$, and the release rate was enhanced in a purposely prepared medium containing extracellular microbial enzymes from rat caecal and colonic contents. This was consistent with the presence of larger surface pores in systems that were incubated in the enzymecontaining medium than in those exposed to the enzyme-free $\mathrm{pH} 6.8$ fluid, as observed in the relevant SEM photomicrographs.

Pellets containing chitosan as a matrix-forming agent and rutin, which is cleaved by colonic glucosidases to give the anti-inflammatory and antioxidant flavonoid quercetin, 
were coated with a combination of chitosan and sodium alginate $(5: 95, \mathrm{w} / \mathrm{w})[64]$. This formulation was designed to provide a potential treatment for mild-to-moderate chronic colitis. Pellets coated up to a $18 \%$ weight gain, after withstanding $\mathrm{pH} 3.0,6.8$ and 7.5 media without enzymes, released the majority of their drug content in a pH 6.0 fluid enriched with $\beta$-glucosidases. These pellets demonstrated to more effectively control symptoms of transmural colitis in the rat than peroral and rectal solutions of rutin.

\section{Natural gum-based coatings}

Galactomannans are heteropolysaccharides with a linear mannose backbone and side galactose groups. Among them, guar gum, extracted from guar seeds, was studied as a film-coating agent for colon-targeted drug release $[65,66]$. Different guar gum viscosity grades were applied to 5-FU or indomethacin-layered pellets with the aim of attaining a slowly water-swelling polymer barrier prone to enzymatic degradation when exposed to colonic enzymes. Externally, an enteric coating based on Eudragit FS was added. In vitro testing showed an acceleration in drug release when a $\mathrm{pH} 6.5$ phosphate buffer containing galactomannanase was employed. Double-coated pellets were then administered to dogs giving rise to later and lower drug absorption as compared with Eudragit FS-coated and uncoated pellets.

Another naturally-occurring gum, xanthan gum, was proposed for use as a colon delivery agent. Budesonide pellets provided with an inner layer (12\% weight gain) of such a polysaccharide, a Eudragit NE /Eudragit L intermediate layer (7:3 weight ratio, $30 \%$ weight gain) and a Eudragit FS outer layer (25\% weight gain) were judged as promising based on in vitro release results [67]. Tableted pellets proved to maintain their initial in vitro performance.

Amylose-, starch- and starch derivative-based coatings 
Amylose, the linear polymer of starch, has largely been exploited for colon targeting because its glassy amorphous form resists the action of pancreatic $\alpha$-amylase, in the small intestine, while being fermented by the colonic microbiota [68]. Amylose was sprayed, as a water dispersion in admixture with EC (1:4, w/w), onto pellets containing 5-ASA or ${ }^{13} \mathrm{C}$-labelled glucose $[69,70]$. No failure of the resulting coating was observed when $\mathrm{HCl} 0.1 \mathrm{M}$ enriched with pepsin and phosphate buffer $\mathrm{pH} 7.2$ enriched with pancreatin were sequentially used as the release media, while their fermentation was prompted by human faecal inocula and large bowel bacteria. A $4.8 \%$ weight gain was found to yield the most appropriate performance for colon delivery. By non-invasive ${ }^{13} \mathrm{CO}_{2}$ breath testing and $\gamma$-scintigraphic imaging, carried out in 8 fasting volunteers, it was possible to correlate the time of first detection of ${ }^{13} \mathrm{CO}_{2}$, exhaled on fermentation of ${ }^{13} \mathrm{C}$-labelled glucose from the test pellets, with colon arrival of inert analogous pellets concomitantly administered [71]. The feasibility of employing the amylose/EC-based coating mixture for dosage forms containing poorly heat- or water-stable drug molecules was explored by making use of organic solvents [72]. After assessing their compatibility, an organic solution of EC in ethyl lactate, propanol or ethanol and a water dispersion of amylose-1-butanol complex were blended to give different weight ratios between amylose and EC: 1:4, 1:2, 1:1 and 3:2 [72,73]. Among these coating compositions, the one having 1:1 amylose/EC ratio and weight gain of $15 \%$ was judged suitable for achieving the expected fast release under simulated colonic conditions while avoiding drug release in the upper intestine. Therefore, higher amylose percentages and coating levels were needed to obtain in vitro results that may compare to those of aqueous spray-coated formulations. 
A study of amylose/EC (1:3)-coated pellets $v$ s. Eudragit S-coated ones, both with a $20 \%$ weight gain, seemed to indicate that, a more reliable in vivo performance would be obtained in the case of the microbiota-dependent formulation [74]. Indeed, pellets containing theophylline, coated with the amylose/EC blend by aqueous spray-coating, were administered to 8 fasted volunteers along with ${ }^{99 \mathrm{~m}}$ Tc-labelled inert beads of analogous size and density, demonstrating that the drug was absorbed when dosage forms reached the colonic region. On the other hand, an early and less reproducible release performance was exhibited by pellets coated with Eudragit S. With the aim of in-depth investigating the effect of post-prandial pancreatic enzyme secretion and of a possibly prolonged gastric residence time on the performance of the amylose/EC coating, the same pellets were administered to 7 volunteers in the fasted and fed state together with the radiolabelled inert beads [75]. By combining different techniques, i.e. assay of the drug recovered from faecal slurries, measurement of theophylline plasma levels and $\gamma$-scintigraphy, it was assessed that $92 \%$ of the drug was released to the colon regardless of the feeding state of the subjects, and no statistically significant differences were found between the amount of theophylline absorbed in the fasted and the fed state. Moreover, prednisolone sodium metasulfabenzoate pellets provided with the amylose/EC coating (COLAL-PRED) entered late-stage clinical trials and proved effective in the local therapy of ulcerative colitis [76].

The outcome of using high-amylose maize starches with different amylose percentages was recently evaluated since it was reported that, as a result of the thermal treatment involved by spray-coating the relevant films would selectively be digested by colonic bacterial amylases [77]. The high-amylose maize starches under investigation, mixed with EC (1:2 to 1:5), were thus sprayed onto 5-ASA pellets [78,79]. By in vitro 
testing, it was demonstrated that a 1:2 Hylon ${ }^{\circledR}$ VII/EC coating of approximately $45 \mu \mathrm{m}$ lost integrity in simulated colonic fluid containing a microbial $\alpha$-amylase, after maintaining its barrier properties in simulated gastric and intestinal fluids, in the presence or absence of enzymes. These pellets, when administered to rabbits, showed $\mathrm{t}_{\max }$ at approximately $8 \mathrm{~h}$ post-dose, probably associated with a distal intestinal release and absorption of the drug [80]. However, the 5-ASA dose was only partly released because an average drug content of $38.3 \%$ was still found in the pellets recovered from the faeces after the $24 \mathrm{~h}$ study.

Interestingly, among a variety of starch derivatives investigated as possible components of colon targeting coatings, Nutriose ${ }^{\circledR}$ and Eurylon ${ }^{\circledR} 6$ HP-PG turned out to potentially undergo enzymatic degradation in the large bowel also in IBD patients [8183]. 5-ASA and theophylline pellets were coated with different blends of these amylose derivatives with EC (1:2-1:5 weight ratios) up to 5-20\% weight gains [84-87]. High coating levels and EC content were needed to effectively hinder the drug liberation in fluids simulating upper GI conditions, which did not prevent a rapid release when the pellets were tested in culture media mimicking the IBD colon environment.

High-amylose corn starches, acetylated to various degrees, were explored for use as film-coating agents intended for colon delivery with no addition of hydrophobic polymer materials [88]. Pellets containing 5-ASA, bovine serum albumin, hepatocyte growth-promoting factor or insulin were indeed coated with the acetylated starch derivatives by organic spray-coating up to 5-11\% weight gains. By adjusting variables such as the degree of polymer acetylation, coating level, amount of plasticizer and type as well as load of the bioactive compound, less than $12 \%$ of the drug was lost in simulated upper GI fluids, and an increased release in $\mathrm{pH} 7.0$ phosphate buffer was 
observed. However, the role of microbial breakdown failed to be assessed as the $\mathrm{pH} 7.0$ phosphate buffer employed contained no enzymes.

\section{Azo-polymer-based coatings}

Besides polysaccharide materials of natural origin, synthetic azo-polymers were also used for the attainment of enzymatically degradable film coatings aimed at colonic release [89]. Safety issues and the need for organic solvents, which would poorly be aligned with current regulatory compliance requirements, represent the main limit to their success.

In the 80 's, a copolymer of styrene and hydroxyethylmethacrylate (HEMA) crosslinked with divinylazobenzene or substituted divinylazobenzenes and liable to bacterial azoreduction in the colon, was employed to coat insulin-loaded pellets [90]. Rats with pharmacological diabetes mellitus showed a prolonged reduction in the blood glucose levels three hours after administration of the pellets, whereas a slighter effect was seen in non-diabetic rodents.

Pellets containing different water-soluble drugs, were coated with linear polyurethanes comprising alternating azoaromatic, hydrophobic and hydrophilic segments $[91,92]$. Their in vitro release profiles could be modified through proper changes in the polymer composition: for example, by increasing the percentage of the azo-component, release in the bacterial culture was speeded up and, by increasing the ratio between the hydrophilic and hydrophobic components, the onset of drug liberation was brought forward. On the other hand, an increase in the molecular weight of the polyurethane resulted in reduced release rate in human intestinal culture. Segmented polyurethanes were also employed to coat budesonide-layered pellets then coated with Eudragit L for gastroresistance, Administered to rats with pharmacologically-induced 
colitis, the coated pellets generally displayed a higher efficacy than an oral solution or a rectal enema of the anti-inflammatory drug [93]. Pellets loaded with bovine insulin or $\left(\mathrm{Asu}^{1,7}\right)$ eel calcitonin, with or without the protease inhibitor camostat mesilate, and coated with a segmented polyurethane gave rise in the rat model to slight hypoglicaemic or hypocalcaemic effects that were maintained over a period of several hours and markedly increased in the presence of the enzyme inhibitor [94]. However, the onset of such effects was relatively faster than the measured pellet transit to the colon.

\section{Pellets with pH-sensitive film coatings}

\section{Enteric-soluble coatings}

Polymethacrylates are extensively used as coating agents for the achievement of colon delivery. In this respect, is well known that Eudragit $\mathrm{S}$, soluble above $\mathrm{pH} 7.0$, and Eudragit L, soluble above $\mathrm{pH}$ 5.5, are contained in various commercially-available drug products intended for the treatment of IBD [95]. These polymers can be applied by both organic and aqueous spray-coating, in solution or dispersion, respectively. In order to avoid early failure of the relevant coatings in upper intestinal regions, higher coating levels thereof are generally required than in conventional enteric dosage forms.

In the early 90's, Eudragit S was coupled with succinic acid to coat diltiazem hydrochloride pellets, and an EC film was added [96]. The use of the acid was meant to prolong the lag phase due to a slower dissolution of the polymethacrylate in the enteric fluids. Such pellets provided in vivo lag times possibly suitable for colon targeting

High-dose sodium butyrate pellets aimed at supplementation of the fatty acid, which is a preferential substrate for coloncytes, were coated with a mixture of Eudragit $\mathrm{S}$ and Eudragit L (1:1, w/w), sprayed as an organic solution [97]. These pellets showed an in 
vitro lag time of almost $6 \mathrm{~h}$ in $\mathrm{pH} 6.8$,and were also administered to butyrate-deprived rats. Although the release of the bioactive compound was assessed to occur in the caecal and colonic regions, no trophic effect on the mucosa was observed, probably due to the lack of short-chain fatty acids other than butyrate or to an insufficient dose of the latter.

A mixture of Eudragit S and Eudragit L was also employed, as an organic solution, to coat indomethacin-layered pellets [98]. The composition of the coating solution , and the final coating level were optimized by a full-factorial experimental design. The optimum formulation, having a Eudragit S/Eudragit L ratio of 4:1 (w/w) and a weight gain of $20 \%$, allowed release to be prevented in $\mathrm{pH} 1.2$ and 6.5 media. The drug liberation slowly took place at $\mathrm{pH} 6.8$ and continued faster at $\mathrm{pH} 7.2$, considered representative of the terminal ileum. Eudragit RS was subsequently added to the Eudragit S/Eudragit L combination in an attempt to modify the release rate after the lag phase [99]. An optimized formulation (20:64:16 weight ratio among the three polymers, respectively; $10 \%$ overall weight gain) was reported to yield the desired in vitro results.

Eudragit $\mathrm{S}$ was used as an aqueous dispersion to coat 5-ASA pellets, prepared by extrusion-spheronization, up to a $30 \%$ weight gain [100]. The proposed formulation was intended for a sustained release of the drug throughout the large bowel. Combined GI transit simulation and in vitro release results were relied on to predict that more consistent prolonged release of the drug to the colon could be obtained from such dosage form than from different marketed 5-ASA products (Pentasa ${ }^{\circledR}$ and Asacol ${ }^{\circledR}$ ). In the presence of cushioning/disintegrant/binding excipients, the Eudragit S-coated 5ASA pellets were compacted into tablets without being damaged or losing the original release properties $[100,101]$. 
5-ASA pellets, containing a 1:1 mixture of carbomer 940 and hydroxypropylcellulose (HPC) for bioadhesion, were first coated with EC (18\% weight gain) and afterwards with an organic solution of Eudragit S (28\% weight gain) [102]. In vitro, the release of 5-ASA was prevented in fluids with acidic $\mathrm{pH}(\mathrm{HCl} 0.1 \mathrm{~N}$ and phosphate buffer $\mathrm{pH}$ 6) and started in phosphate buffer $\mathrm{pH}$ 7.4. In vivo, a significant and dose-dependent improvement in clinical, histological and biochemical signs of pharmacologically-induced colitis were observed following intra-gastric administration of the double-coated pellets to rats.

Aiming at a chronopharmaceutical treatment for nocturnal asthma, a statisticallyoptimized formulation of Eudragit S and Eudragit RL (1:4, w/w) was applied to theophylline pellets [103]. In the rabbit, such coated pellets showed a lag phase of $5 \mathrm{~h}$ prior to detection of the drug in the plasma, which was considered a promising result.

For the purpose of overcoming the often reported failure of Eudragit $\mathrm{S}$ coatings to timely and completely dissolve in the colon, a novel dual coating was proposed comprising an inner layer of partially neutralized Eudragit $S$ and of a buffer agent, and an outer standard coat of Eudragit S [104]. At the threshold $\mathrm{pH}$, a prompter dissolution was expected from partially neutralized Eudragit $\mathrm{S}$ than from the acid polymer as such. The outer layer would prevent the protonation of the polymer contained in the internal one during gastric residence. Such technology was applied to mucoadhesive pellets containing prednisolone [105]. As compared with pellets coated with Eudragit S only, those provided with the double layer exhibited faster in vitro dissolution of the coating and better mucoadhesive properties, which could both help increase the amount of drug released to the colon. 
Eudragit FS 30D was presented as an alternative to Eudragit $\mathrm{S}$ in order to better match the slightly alkaline $\mathrm{pH}$ that may be found in the proximal colon of ulcerative colitis sufferers [106]. 5-ASA pellets were thus coated with Eudragit FS 30D and, tested in biorelevant fluids, showing a slow liberation of the drug in a $\mathrm{pH}$ 6.8-7.2 range while a rapid release was observed at $\mathrm{pH}$ 7.5. Notably, pellets coated with Eudragit S exhibited a fast release of 5-ASA also at $\mathrm{pH} 7.2$, which was considered representative of the jejunum and ileum fluid. Like Eudragit S, Eudragit FS was proved to perform consistently independent of the osmolarity of the medium and of the presence of some physiological surfactants.

A more complex delivery system, consisting in 5-ASA pellets with a double coat, an inner Eudragit RS/Eudragit RL (4:1, w/w) layer and a Eudragit FS outer one, was statistically designed in order to attain a prolonged release of the drug throughout the lower small bowel and the colon that may meet the needs of once-daily dosing regimen $[107,108]$. These double-coated pellets, loaded with caffeine as a tracer, were compared in vivo with Eudragit FS-coated ones [109]. The formulations under investigation were administered to 12 fasting volunteers together with lactose ${ }^{13} \mathrm{C}$-ureide, used as a marker for oro-caecal transit because it undergoes selective fermentation by colonic bacteria. The results obtained by combining pharmacokinetic and breath testing data demonstrated that the Eudragit RS/Eudragit RL layer was needed for the achievement of a prolonged liberation of the drug in the distal small intestine and the colon. Pellets with analogous double coatings based on Eudragit RS/Eudragit RL and Eudragit FS were proposed for selective colonic release of budesonide in ulcerative colitis patients [110]. The percentages of the three coating polymers were statistically optimized. Weight 
gains ranged between 2-8\% and 10-30\% with Eudragit RS/Eudragit RL and Eudragit FS, respectively.

More recently, an external Eudragit FS 30D coat was coupled with an inner Eudragit NE film for prolonged release of 5-FU to the colonic region [111]. The pellets, prepared by extrusion-spheronization, were statistically optimized with respect to spheronization conditions and coating levels. Weight gains of $15 \%$ with both acrylic polymers were considered appropriate for the attainment of a satisfactory in vitro release performance.

Eudragit FS was also used to coat meloxicam/ $\beta$-cyclodextrin-layered pellet cores with the aim of preparing a delivery system potentially suitable for the chemoprevention of colorectal adenocarcinoma [112]. An interlayer of HPMC was applied to avoid interactions between the drug and the polymethacrylate. After simulated gastric fluid, the pellets were tested at various slightly acidic to slightly alkaline $\mathrm{pH}$ values giving rise to a fast release at $\mathrm{pH} 7.2$ or above, although only at $\mathrm{pH} 7.4$ the release was not preceded by any lag phase. When these pellets were administered to gastric acidityregulated beagle dogs, the drug absorption turned out delayed, slower and reduced in extent with respect to uncoated cores.

Kollicoat ${ }^{\circledR}$ MAE 30DP, an aqueous dispersion of methacrylic acid and ethyl acrylate copolymer, was applied to extrusion-spheronization metronidazole pellets containing chitosan (10\%) as an enzymatically degradable matrix excipient and provided with a polyvinyl acetate (Kollicoat SR 30D) coat for prolonged release purposes [113]. The use of statistically optimized amounts of coating polymers and chitosan in the cores resulted in no release at $\mathrm{pH} 1.2$ and a slow drug liberation in fluids with increasing $\mathrm{pH}$ values (6.0-7.2). 
Besides polymethacrylates, hydroxypropylmethylcellulose acetate succinate (HPMCAS) and cellulose acetate phthalate (CAP) were investigated as enteric coating polymers for colon delivery. Aqueous formulations of HPMCAS (Aqoat AS-HF) or CAP (Aquateric), were employed to coat ibuprofen or furosemide pellets manufactured by wet granulation using enteric-soluble polymers (Eudragit S or Aqoat AS-HF) as binders [114]. Pellets with weight gains in the range 10-30\% were then tested in media with different $\mathrm{pH}$ values $(5.0,6.8,7.4)$ and administered to fasting as well as fed volunteers. HPMCAS coatings gave rise to longer in vitro and in vivo delay periods. Moreover, release and absorption profiles from HPMCAS-coated pellets were slower, especially when such a polymer was also present in the core as the binding agent. With the aim of extending the lag phase duration, organic acids, such as citric or succinic acid, were incorporated in the pellet core [115]. Although the acid inclusion resulted in delayed in vitro release, no effect was evident in vivo.

\section{Acid-soluble coatings}

Acid-soluble polymers have also been employed in order to attain $\mathrm{pH}$-dependent colonic release. In this instance, the coat would be intended to dissolve in the caecum and right colon as a consequence of the local $\mathrm{pH}$ decrease caused by the presence of acidic microbial fermentation products. Therefore, the acid-soluble layer needs to be combined with a gastroresistant outer film to avoid premature failure in the stomach environment. Eudragit $\mathrm{E}$, a basic polymethacrylate soluble at $\mathrm{pH}<5.0$, was employed to coat dexamethasone minitablets [24]. The release from the coated system occurred in 10-50 min when acidic media were used while taking several hours at $\mathrm{pH}$ 6.8. In this medium, a marked influence of the coating extent and composition of the core was observed. Carbopol 934, added to the tablet formulation, promoted the erosion and 
rupture of non-ionized Eudragit E due to its swelling behaviour, thus shortening the lag phase prior to release [116]. The application of an outer HPMCAS film and of a lowviscosity HPC layer, to separate the oppositely-charged internal and external coats, did not alter the performance of the Eudragit E one.

Eudragit E was also present in a tri-layer system consisting of budesonide pellet cores containing citric acid, an inner HPMC film, an intermediate Eudragit E layer containing microcrystalline cellulose as a pore former and an outer enteric coating of HPMCAS [117]. Pellets having $20 \%$ of citric acid in the core, $30 \%$ of pore former in the Eudragit E layer and weight gains of $6 \%, 30 \%$ and $15 \%$ relevant to the inner, intermediate and outer coatings were selected for in vivo testing in rats with a pharmacologically-induced colitis model. This formulation was proved more effective than saline solution, placebo coated pellets, uncoated pellets, budesonide solution and budesonide enema in improving clinical and macroscopic as well as microscopic signs of disease.

\section{Pellets with time-dependent film coatings}

Pellets coated with rupturable, erodible or permeable layers, having intrinsic delaying ability, would not only be suitable for chronotherapeutic purposes but also for colonic release $[31,118,119]$. The coatings used in time-dependent colon delivery systems are expected to impart, through interaction with aqueous fluids, a programmable lag phase that approximately corresponds to SITT, so that drug release may be hindered along the small bowel and occur when the dosage form reaches the large intestine. Because the residence of solid substrates in the stomach is of unpredictable duration, such coatings should be shielded from gastric fluid. Moreover, it 
is necessary that their performance is poorly be affected by physiological variables, such as $\mathrm{pH}$ and enzymatic breakdown.

\section{Rupturable coatings}

Rupturable coatings are moderately permeable polymeric films that are subject to timely break-up because of the pressure that develops within the core formulation upon water inflow. The delay time depends on the composition and thickness of the coating. EC is especially used as a rupturable film-forming agent.

In the Time-Controlled Explosion System (TES), drug-loaded sucrose seeds were coated with a low-substituted hydroxypropylcellulose (L-HPC) layer, responsible for providing the swelling pressure needed for disruption and release, and with an EC outer film [120-122]. A sufficient L-HPC coating level was necessary for a pulsatile release performance to be attained. In vitro release results were consistent irrespective of the amount and solubility of the loaded drug, of the pellet size and of the fluid $\mathrm{pH}$. Furthermore, in vitro and in vivo lag times, the latter collected from dog and human pharmacokinetic studies, turned out to be in agreement [123-125]. TES having more extended in vitro lag times showed reduced bioavailability, which could be attributed to the lower volume of water present in the distal intestine or to a greater first-pass effect associated with the slower absorption of the drug.

In an analogous delivery system, croscarmellose sodium (Ac-Di-Sol ${ }^{\circledR}$ ) was employed to prepare the swelling layer below the EC one [126,127]. Pacetamol pellets coated with Ac-Di-Sol ${ }^{\circledR}$ and, externally, with an EC film of varying thickness were administered to healthy volunteers for an in vivo study. A progressive decrease in the amount of drug absorbed was observed with increasing EC coating levels and, again, this was ascribed to the limited water content of the colonic fluid. A combination 
between Ac-Di-Sol ${ }^{\circledR}$ and EC is also found in a delivery system based on isosorbide 5mononitrate pellets prepared by extrusion-spheronization [128]. The system was designed for the chronotherapy of cardiovascular disease and claimed as advantageous over prolonged-release formulations of the parent drug, isosorbide dinitrate, in limiting tolerance issues. In beagle dogs, the system yielded programmable lag times.

The use of low- and high-viscosity HPMC as the swelling agent, in place of superdisintegrants, was also reported [129]. Pellets containing glipizide, coated up to $20 \%$ and 5\% weight gains with low-viscosity HPMC and EC, respectively, or 5\% and $10 \%$ weight gains with high-viscosity HPMC and EC, were combined with uncoated ones in order to give a two-pulse release performance. A 6-8 h in vitro lag phase elapsed between the former and the latter pulse. This was considered beneficial to the chronic treatment of type 2 diabetes because of a reduced dosing frequency and, therefore, improved patient compliance.

Cellulose acetate, which is the main component of semipermeable membranes, was used as the rupturable film-forming polymer instead of EC [130]. In this instance, the core expansion was due to the osmo-active agent sodium chloride contained in the pellet core that would draw water from the outer medium. Plasticizers with different physicochemical properties, added to the coating, prolonged the lag phases as a function of their degree of lipohilicity in view of a decrease in the aqueous permeability of the resulting film [131]. On the other hand, the lag phase was shortened by increasing the amount of talc in the film.

\section{Erodible coatings}

Although erodible coats with inherent delaying ability were by far more frequently employed in single-unit formulations, reasonably because of the relatively high coating 
levels necessary for lag phases of suitable duration to be attained, a pulsatile delivery system provided with a low-viscosity HMPC coating (Chronotopic ${ }^{\mathrm{TM}}$ ) was recently proposed in a multiple-unit configuration starting from immediate-release minitablet cores $[132,133]$. This involved that a moderately permeable, flexible film was applied onto the swellable/erodible coating in order to temporarily hinder the penetration of water into the latter thus extending the delay time and allowing the HPMC coating level to be reduced. The neutral polymethacrylate Eudragit ${ }^{\circledR} \mathrm{NE}$ was used as the film-forming agent, whereas various superdisintegrants were added as non-conventional pore formers [134]. Once the proper thickness and composition of such films had been assessed, these were proved to considerably prolong the lag phase duration without impacting on the subsequent rapid release of the active ingredient [133]. Paracetamol was used as an analytical tracer because of its ease of handling, simple assay and stability characteristics [135]. Because the Chronotopic ${ }^{\mathrm{TM}}$ technology was demonstrated feasible not only when dealing with low molecular weight drugs but also with insulin, the system in its multiple-unit configuration was considered as an interesting formulation candidate for delivery of the protein and of appropriate adjuvants to the colonic region [136-138].

\section{Permeable coatings}

Permeable coatings, not intended for rupturing but as diffusive barriers, were also used for pulsatile release purposes through exploitation of the initial lag phase connected with the penetration of water into the core and the activation of the outward diffusion of the drug. After the delay time, dependent on the thickness and permeability characteristics of the membrane, the drug would generally be released slowly because the rate of the process is controlled by the membrane itself. In the Sigmoidal Release 
System (SRS), nonpareil seeds were coated with a blend of the active ingredient and succinic acid and then with Eudragit ${ }^{\circledR}$ RS [139-141]. The organic acid was added in order to enhance the rate of release. Indeed, following its dissolution and partial ionization, it may interact with quaternary ammonium groups of the polymethacrylate, as an anion, and with the lipophilic macromalucular chains of the same polymer as the parent acid form. This would lead to a looser polymer network with decreased barrier functions. Irrespective of the coating level and, therefore, of the extent of delay,, a relatively short diffusive phase preceded the fast release of most of the drug content, thus yielding the typical sigmoidal patterns obtained in vitro. The performance of this system was studied in beagle dogs, and an agreement between in vitro and in vivo data was found although the slightly soluble drug theophylline was not quantitatively released, most likely due to the low water content of distal intestinal fluids.

Eudragit ${ }^{\circledR}$ RS was also employed as the coating agent for a multiple-unit formulation based on nonpareil cores loaded with diltiazem hydrochloride [142]. The system was intended for delivery of drugs with $\mathrm{pH}$-independent aqueous solubility to different gastrointestinal sites, and the lag phase duration was a function of the coating level, amount of plasticizer in the coat and curing time.

\section{Conclusions}

Colon delivery systems based on coated pellets have been designed to exploit physiological $\mathrm{pH}$ changes within the small and large bowel, undergo enzymatic degradation by the colonic microbiota or delay the onset of release according to the time required for dosage forms to reach the colon district. 
The majority of the formulations proposed comprise matrix pellets prepared by extrusion-spheronization as cores, loaded with 5-ASA or other drugs indicated for colonic pathologies. Indeed, despite a number of tentative investigations aimed at enhancing intestinal protein absorption, the main area of interest of colon release still resides in the local delivery of anti-inflammatory drugs for the treatment of IBD. Such pellets are mostly film-coated with hydrophilic polymers of natural origin, or relevant blends with insoluble materials, susceptible to microbial degradation in the large bowel. The overall performance of the resulting coated systems often depends on a multiplicity of factors, among which the physico-chemical and formulation characteristics of the coating agent or mixture, thickness of the applied layer and manufacturing technique employed play major roles. Evaluation of their release characteristics has commonly been carried out in vitro, by means of differing testing procedures. For instance, media with $\mathrm{pH}$ in an array of values have been used to mimic the colonic environment, and microbial enzymes, bacterial cultures as well as intestinal homogenates/contents have seldom been added to test fluids. While this may have a negligible impact on the outcome of $\mathrm{pH}$ - and time-controlled delivery systems, the potential of microbiotaactivated formulations could not be assessed in the lack of the concerned enzymatic activity. In vivo evaluation, when undertaken, has mainly been performed in rats or other animal models. Only in a very limited number of cases, $\gamma$-scintigraphic studies have been conducted in humans, proving the effectiveness of the formulation technologies under investigation at yielding selective delivery of drugs into the colon.

Notably, there also are drug products available on the marketplace, containing high doses of 5-ASA for the treatment of IBD, that are based on pellets with $\mathrm{pH}$-dependent coatings $\left(\right.$ Claversal $^{\circledR}$ Micropellets, Salofalk $^{\circledR}$ Granustix $^{\circledR}$ ) or EC films $\left(\right.$ Pentasa $^{\circledR}$ ). 
However, the issues of early or incomplete disintegration and drug release are likely to be encountered. Actually, due to the high intra- and inter-subject variability affecting the physiological parameters exploited, each triggering mechanism involved may fail to work as expected, thus impairing the attainment of a quantitative drug release to the large intestine. These drawbacks could partially be overcome by an increase in the drug dose, although safety and cost-effectiveness aspects would need to be taken into account. The risk of failure of a colon delivery system is even larger when the biological parameter the formulation relies on is altered by pathological conditions, which is usually the case when a local therapeutic goal is pursued.

In this respect, multiple-unit formulations, generating a number of independent coated subunits upon intake, may to a lesser extent be influenced by this variability and, therefore, could improve the performance consistency. Besides, their slower transit along the colon as compared with single units may aid a complete release of the drug to the target site, and the relevant size would enhance contact with intestinal aqueous fluid that has been found to form isolated pockets of very limited volume rather than a continuous milieu [143-145]. Moreover, innovative formulation designs based on a combination of two or more targeting mechanisms may reasonably offer, versus simpler strategies relying on each single mechanism, better chances of colonic release.

\section{References}

1. Ghebbre-Sellassie I. Pharmaceutical Pelletization Technology. New York and Base: Marcel Dekker, 1989. 
2. Soh JLP, Srimanta S, Heng PWS, Liew VC. Pelletization Techniques. In Encyclopedia of Pharmaceutical Science and Technology, Fourth Edition. New York: Taylor and Francis, 2013.

3. Politis SN, Rekkas DM. Pelletization processes for pharmaceutical applications: A patent review. Recent Pat Drug Deliv Formulation 2011;5:61-78.

4. Podczeck F, Jones BE. Pharmaceutical Capsules. London: Pharmaceutical Press, 2004.

5. Wise DL. Handbook of Pharmaceutical Controlled Release Technology. Boca Raton: CRC Press, 2000.

6. Grassi M, Zema L, Sangalli ME, et al. Modeling of drug release from partially coated matrices made of a high viscosity HPMC. Int J Pharm 2004;276:107-14.

7. Sangalli ME, Zema L, Maroni A, et al. Influence of betacyclodextrin on the release of poorly soluble drugs from inert and hydrophilic heterogeneous polymeric matrices. Biomaterials 2001; 22:2647-51

8. McGinity JW, Felton LA. Aqueous Polymeric Coatings for Pharmaceutical Dosage Forms Third Edition. Boca Raton: CRC Press, 2013.

9. Sauer D, Cerea M, Dinunzio J, McGinity J. Dry powder coating of pharmaceuticals: A review. Int J Pharm 2013;457:488-502.

10. Cerea M, Zema L, Palugan L, Gazzaniga A. Recent developments in dry coating. Pharm Technol Eur 2008;20:40-44.

11. Vecchio C, Fabiani F, Sangalli ME, et al. Rotary tangential spray technique for aqueous film coating of indobufen pellets. Drug Dev Ind Pharm 1998;24:269-74. 
12. Gazzaniga A, Sangalli ME, Bruni G, et al. The use of $\beta$-cyclodextrin as a pelletization agent in the extrusion/spheronization process. Drug Dev Ind Pharm 1998;24:869-73.

13. Di Pretoro G, Zema L, Gazzaniga A, et al. Extrusion-spheronisation of highly loaded 5-ASA multiparticulate dosage forms. Int J Pharm 2010;402:153-64.

14. Di Pretoro G, Zema L, Palugan L, et al. Optimisation and scale-up of a highlyloaded 5-ASA multi-particulate dosage form using a factorial approach. Eur J Pharm Sci 2012;45:158-68.

15. Bianchini R, Bruni G, Gazzaniga A, Vecchio C. Influence of extrusionspheronization processing on the physical properties of d-Indobufen pellets containing pH adjusters. Drug Dev Ind Pharm 1992;18:1485-503.

16. Bianchini R, Bruni G, Gazzaniga A, Vecchio C. d-Indobufen extended-release pellets prepared by coating with aqueous polymer dispersions. Drug Dev Ind Pharm 1993;19:2021-41

17. Gazzaniga A, Giordano F, Sangalli ME, Zema L. Oral colon-specific drug delivery: Design strategies. STP Pharma Prat 1994;4:336-43.

18. Gazzaniga A, Maroni A, Sangalli ME, Zema L. Time-controlled oral delivery systems for colon targeting. Expert Opin Drug Deliv 2006;3:583-97.

19. Patel MM, Amin AF. Recent trends in microbially and/or enzymatically driven colon-specific drug delivery systems. Crit Rev Ther Drug Carrier Syst 2011;28:489-552.

20. Rubinstein A. Microbially controlled drug delivery to the colon. Biopharm Drug Dispos 1990;11:465-75. 
21. Sinha VR, Kumria R. Microbially triggered drug delivery to the colon. Eur J Pharm Sci 2003;18:3-18.

22. Edwards C. Physiology of the colorectal barrier. Adv Drug Deliv Rev 1997;28:173-90.

23. Nugent SG, Kumar D, Rampton DS, Evans DF. Intestinal luminal pH in inflammatory bowel disease: Possible determinants and implications for therapy with aminosalicylates and other drugs. Gut 2001;48:571-77.

24. Leopold CS, Eikeler D. Eudragit ${ }^{\circledR} \mathrm{E}$ as coating material for the $\mathrm{pH}$-controlled drug release in the topical treatment of inflammatory bowel disease (IBD). J Drug Target 1998;6:85-94.

25. Davis SS. The design and evaluation of controlled release systems for the gastrointestinal tract. J Control Release 1985;2:27-38.

26. Ofori-Kwakye K, Fell JT, Sharma HL, Smith AM. Gamma scintigraphic evaluation of film-coated tablets intended for colonic or biphasic release. Int J Pharm 2004;270:307-13.

27. Ibekwe VC, Khela MK, Evans DF, Basit AW. A new concept in colonic drug targeting: a combined $\mathrm{pH}$-responsive and bacterially-triggered drug delivery technology. Aliment Pharmacol Ther 2008;28:911-16.

28. Marvola T, Marvola J, Kanerva H, et al. Neutron activation based gamma scintigraphic evaluation of enteric-coated capsules for local treatment in colon. Int J Pharm 2008;349:24-29.

29. Fadda HM, McConnell EL, Short MD, Basit AW. Meal-induced acceleration of tablet transit through the human small intestine. Pharm Res 2009;26:356-60. 
30. Wilson CG. The transit of dosage forms through the colon. Int J Pharm 2010;395:17-25.

31. Maroni A, Zema L, Del Curto MD, et al. Oral pulsatile delivery: Rationale and chronopharmaceutical formulations. Int J Pharm 2010;398:1-8.

32. Conte U, Colombo P, La Manna A, et al. A new Ibuprofen pulsed release oral dosage form. Drug Dev Ind Pharm 1989;15:2583-96.

33. Friend DR. New oral delivery systems for treatment of inflammatory bowel disease. Adv Drug Deliv Rev 2005;57:247-65.

34. Klotz U, Schwab M. Topical delivery of therapeutic agents in the treatment of inflammatory bowel disease. Adv Drug Deliv Rev 2005;57:267-79.

35. Krishnaiah YSR, Satyanarayana V, Kumar BD, Karthikeyan RS. Studies on the development of colon-targeted delivery systems for Celecoxib in the prevention of colorectal cancer. J Drug Target 2002;10:247-54.

36. Krishnaiah YSR, Satyanarayana V, Kumar BD, et al. In vivo pharmacokinetics in human volunteers: Oral administered guar gum-based colon-targeted 5fluorouracil tablets. Eur J Pharm Sci 2003;19:355-62.

37. Sinha VR, Mittal BR, Bhutani KK, Kumria R. Colonic drug delivery of 5fluorouracil: An in vitro evaluation. Int J Pharm 2004;269:101-08.

38. Bourgeois $\mathrm{S}$, Laham $\mathrm{A}$, Besnard $\mathrm{M}$, et al. In vitro and in vivo evaluation of pectin beads for the colon delivery of $\beta$-lactamases. J Drug Target 2005;13:277-84.

39. Khoder M, Tsapis N, Fattal E. Mechanisms of antibiotic resistance and delivery strategies to prevent its emergence. J Drug Deliv Sci Technol 2010;20:407-18. 
40. Haupt S, Rubinstein A. The colon as a possible target for orally administered peptide and protein drugs. Crit Rev Ther Drug Carrier Syst 2002;19:499-551.

41. Bourgeois S, Harvey R, Fattal E. Polymer colon drug delivery systems and their application to peptides, proteins, and nucleic acids. Am J Drug Deliv 2005;3:171204.

42. Maroni A, Zema L, Del Curto MD, et al. Oral colon delivery of insulin with the aid of functional adjuvants. Adv Drug Deliv Rev 2012;64:540-56.

43. Sriamornsak P. Application of pectin in oral drug delivery. Expert Opin Drug Deliv 2011;8:1009-23.

44. Sande SA. Pectin-based oral drug delivery to the colon. Expert Opin Drug Deliv 2005;2:441-50.

45. Ahmed IS. Effect of simulated gastrointestinal conditions on drug release from pectin/ethylcellulose as film coating for drug delivery to the colon. Drug Dev Ind Pharm 2005;31:465-70.

46. Ahmed IS, Ayres JW. Comparison of in vitro and in vivo performance of a colonic delivery system. Int J Pharm 2011;409:169-77.

47. Fan LF, He W, Bai M, et al. Biphasic drug release: Permeability and swelling of pectin/ethylcellulose films, and in vitro and in vivo correlation of film-coated pellets in dogs. Chem Pharm Bull 2008;56:1118-25.

48. He W, Du Q, Cao DY, et al. Study on colon-specific pectin/ethylcellulose filmcoated 5-fluorouracil pellets in rats. Int J Pharm 2008;348:35-45.

49. He W, Du Q, Cao DY, et al. In-vitro and in-vivo studies of pectin/ethylcellulose- 
film-coated pellets of 5-fluorouracil for colonic targeting. J Pharm Pharmacol 2008;60:35-44.

50. Bose A, Elyagoby A, Wong TW. Oral 5-fluorouracil colon-specific delivery through in vivo pellet coating for colon cancer and aberrant crypt foci treatment. Int J Pharm 2014;468:178-86.

51. Semdé R, Amighi K, Devleeschouwer MJ, Moës AJ. Effect of pectinolytic enzymes on the theophylline release from pellets coated with water insoluble polymers containing pectin HM or calcium pectinate. Int J Pharm 2000;197:16979.

52. Semdé R, Amighi K, Devleeschouwer MJ, Moës AJ. Studies of pectin HM/Eudragit ${ }^{\circledR}$ RL/Eudragit ${ }^{\circ}$ NE film-coating formulations intended for colonic drug delivery. Int J Pharm 2000;197:181-92.

53. Hagesaether E, Hiorth M, Sande SA. Mucoadhesion and drug permeability of free mixed films of pectin and chitosan: An in vitro and ex vivo study. Eur J Pharm Biopharm 2009;71:325-31.

54. Ghaffari A, Avadi MR, Moghimi HR, et al. Mechanistic analysis of drug release from theophylline pellets coated by films containing pectin, chitosan and Eudragit® RS. Drug Dev Ind Pharm 2008;34:390-402.

55. Hiorth M, Versland T, Heikkila J, et al. Immersion coating of pellets with calcium pectinate and chitosan. Int J Pharm 2006;308:25-32.

56. Hiorth M, Skoien T, Sande SA. Immersion coating of pellet cores consisting of chitosan and calcium intended for colon drug delivery. Eur J Pharm Biopharm 2010;75:245-53. 
57. Cui F, Yang L, Jin J, Piao H, Lin W, Cun D. Preparation and in vitro evaluation of $\mathrm{pH}$, time-based and enzyme-degradable pellets for colonic drug delivery. Drug Dev Ind Pharm 2007;33:999-1007.

58. Sureshkumar R, Munikumar, Ganesh GNK, et al. Formulation and evaluation of pectin-hydroxypropyl methylcellulose coated curcumin pellets for colon delivery. Asian J Pharm 2009;3:138-42.

59. Gulbake A, Jain SK. Chitosan: A potential polymer for colon-specific drug delivery system. Expert Opin Drug Deliv 2012;9:713-29.

60. Shimono N, Takatori T, Ueda M, et al. Multiparticulate chitosan-dispersed system for drug delivery. Chem Pharm Bull 2003;51:620-24.

61. Kaur K, Kim K. Studies of chitosan/organic acid/Eudragit ${ }^{\circledR}$ RS/RL-coated system for colonic delivery. Int J Pharm 2009;366:140-48.

62. He W, Fan LF, Bai M, et al. Chitosan/Kollicoat SR 30D film-coated pellets of aminosalicylates for colonic drug delivery. J Pharm Sci 2010;99:186-95.

63. Omwancha WS, Mallipeddi R, Valle BL, Neau SH. Chitosan as a pore former in coated beads for colon specific drug delivery of 5-ASA. Int J Pharm $2013 ; 441: 343-51$

64. Rabišková M, Bautzová T, Gajdziok J, et al. Coated chitosan pellets containing rutin intended for the treatment of inflammatory bowel disease: In vitro characteristics and in vivo evaluation. Int J Pharm 2012;422:151-59.

65. Ji C, $\mathrm{Xu} \mathrm{H}, \mathrm{Wu} \mathrm{W}$. In vitro evaluation and pharmacokinetics in dogs of guar gum and Eudragit FS30D-coated colon-targeted pellets of indomethacin. J Drug Target $2007 ; 15: 123-31$ 
66. Ji CM, Xu HN, Wu W. Guar gum as potential film coating material for colonspecific delivery of fluorouracil. J Biomater Appl 2009;23:311-29.

67. Varshosaz J, Emami J, Tavakoli N, et al. Development and evaluation of a novel pellet-based tablet system for potential colon delivery of budesonide. J Drug Deliv 2012; Article ID 905191.

68. Milojevic S, Newton JM, Cummings JH, et al. Amylose, the new perspective in oral drug delivery to the human large intestine. STP Pharma Sci 1995;5:47-53.

69. Milojevic S, Newton JM, Cummings JH, et al. Amylose as a coating for drug delivery to the colon: Preparation and in vitro evaluation using glucose pellets. $\mathbf{J}$ Control Release 1996;38:85-94.

70. Milojevic S, Newton JM, Cummings JH, et al. Amylose as a coating for drug delivery to the colon: Preparation and in vitro evaluation using 5-aminosalicylic acid pellets. J Control Release 1996;38:75-84.

71. Cummings JH, Milojevic S, Harding M, et al. In vivo studies of amylose- and ethylcellulose-coated [13C]glucose microspheres as a model for drug delivery to the colon. J Control Release 1996;40:123-31.

72. Siew LF, Basit AW, Newton JM. The potential of organic-based amyloseethylcellulose film coatings as oral colon-specific drug delivery systems. AAPS PharmSciTech 2000;1:53-61.

73. Siew LF, Basit AW, Newton JM. The properties of amylose-ethylcellulose films cast from organic-based solvents as potential coatings for colonic drug delivery. Eur J Pharm Sci 2000;11:133-39.

74. McConnell EL, Short MD, Basit AW. An in vivo comparison of intestinal $\mathrm{pH}$ and 
bacteria as physiological trigger mechanisms for colonic targeting in man. $\mathbf{J}$ Control Release 2008;130:154-60.

75. Basit AW, Short MD, McConnell EL. Microbiota-triggered colonic delivery: robustness of the polysaccharide approach in the fed state in man. J Drug Target 2009;17:64-71.

76. McConnell EL, Fadda HM, Basit AW. Gut instincts: Explorations in intestinal physiology and drug delivery. Int J Pharm 2008;364:213-26.

77. Freire CA, Fertig CC, Podczeck F, et al. Starch-based coatings for colon-specific drug delivery. Part I: The influence of heat treatment on the physico-chemical properties of high amylose maize starches. Eur J Pharm Biopharm 2009;72:57486.

78. Freire C, Podczeck F, Veiga F, Sousa J. Starch-based coatings for colon-specific delivery. Part II: Physicochemical properties and in vitro drug release from high amylose maize starch films. Eur J Pharm Biopharm 2009;72:587-94.

79. Freire C, Podczeck F, Veiga F, Sousa J. Influence of the coating formulation on enzymatic digestibility and drug release from 5-aminosalicylic acid pellets coated with mixtures of high-amylose starch and Surelease ${ }^{\circledR}$ intended for colon-specific drug delivery high-amylose starch-based coatings for colonic delivery. Drug Dev Ind Pharm 2010;36:161-72.

80. Freire C, Podczeck F, Ferreira D, et al. Assessment of the in-vivo drug release from pellets film-coated with a dispersion of high amylose starch and ethylcellulose for potential colon delivery. J Pharm Pharmacol 2010;62:55-61.

81. Karrout Y, Neut C, Wils D, et al. Colon targeting with bacteria-sensitive films 
adapted to the disease state. Eur J Pharm Biopharm 2009;73:74-81.

82. Karrout Y, Neut C, Wils D, et al. Characterization of ethylcellulose: Starch-based film coatings for colon targeting. Drug Dev Ind Pharm 2009;35:1190-200.

83. Karrout Y, Neut C, Wils D, et al. Novel polymeric film coatings for colon targeting: How to adjust desired membrane properties. Int J Pharm 2009;371:6470.

84. Karrout Y, Neut C, Wils D, et al. Novel polymeric film coatings for colon targeting: Drug release from coated pellets. Eur J Pharm Sci 2009;37:427-33.

85. Karrout Y, Neut C, Siepmann F, et al. Enzymatically degraded Eurylon 6 HP-PG: Ethylcellulose film coatings for colon targeting in inflammatory bowel disease patients. J Pharm Pharmacol 2010;62:1676-84.

86. Karrout Y, Neut C, Wils D, et al. Enzymatically activated coated multiparticulates containing theophylline for colon targeting. J Drug Deliv Sci Technol 2010;20:193-99.

87. Karrout Y, Neut C, Wils D, et al. Peas starch-based film coatings for site-specific drug delivery to the colon. J Appl Polym Sci 2011;119:1176-84.

88. $\mathrm{Pu} \mathrm{H}$, Chen L, Li X, et al. An oral colon-targeting controlled release system based on resistant starch acetate: Synthetization, characterization, and preparation of film-coating pellets. J Agric Food Chem 2011;59:5738-45.

89. Roldo M, Barbu E, Brown JF, et al. Azo compounds in colon-specific drug delivery. Expert Opin Drug Deliv 2007;4:547-60.

90. Saffran M, Kumar GS, Savariar C. A new approach to the oral administration of 
insulin and other peptide drugs. Science 1986;233:1081-84.

91. Kimura Y, Makita Y, Kumagai T, et al. Degradation of azo-containing polyurethane by the action of intestinal flora: its mechanism and application as a drug delivery system. Polymer 1992;33:5294-99.

92. Yamaoka T, Makita Y, Sasatani H, et al. Linear type azo-containing polyurethane as drug-coating material for colon-specific delivery: Its properties, degradation behavior, and utilization for drug formulation. J Control Release 2000;66:187-97.

93. Tozaki H, Fujita T, Komoike J, et al. Colon-specific delivery of budesonide with azopolymer-coated pellets: Therapeutic effects of budesonide with a novel dosage form against 2,4,6-trinitrobenzenesulphonic acid-induced colitis in rats. J Pharm Pharmacol 1999;51:257-61.

94. Tozaki H, Nishioka J, Komoike J, et al. Enhanced absorption of insulin and (Asu1,7)eel-calcitonin using novel azopolymer-coated pellets for colon-specific drug delivery. J Pharm Sci 2001;90:89-97.

95. Hu MY, Peppercorn MA. MMX mesalamine: A novel high-dose, once-daily 5aminosalicylate formulation for the treatment of ulcerative colitis. Expert Opin Pharmacother 2008;9:1049-58.

96. Klokkers-Bethke K, Fischer W. Development of a multiple unit drug delivery system for positioned release in the gastrointestinal tract. J Control Release $1991 ; 15: 105-12$.

97. Tuleu C, Andrieux C, Cherbuy C, et al. Colonic delivery of sodium butyrate via oral route: Acrylic coating design of pellets and in vivo evaluation in rats. Methods Find Exp Clin Pharmacol 2001;23:245-53. 
98. Akhgari A, Garekani HA, Sadeghi F, Azimaie M. Statistical optimization of indomethacin pellets coated with $\mathrm{pH}$-dependent methacrylic polymers for possible colonic drug delivery. Int J Pharm 2005;305:22-30.

99. Akhgari A, Sadeghi F, Garekani HA. Combination of time-dependent and $\mathrm{pH}-$ dependent polymethacrylates as a single coating formulation for colonic delivery of indomethacin pellets. Int J Pharm 2006;320:137-42.

100. Chuong MC, Christensen JM, Ayres JW. Sustained delivery of intact drug to the colon: Mesalamine formulation and temporal gastrointestinal transit analysis. Pharm Dev Technol 2009;14:116-25.

101. Nguyen C, Christensen JM, Ayres JW. Novel mesalamine-loaded beads in tablets for delayed release of drug to the colon. Pharm Dev Technol 2012;17:73-83.

102. Xu M, Sun M, Qiao H, et al. Preparation and evaluation of colon adhesive pellets of 5-aminosalicylic acid. Int J Pharm 2014;468:165-71.

103. Kadam VD, Gattani SG. Development of colon targeted multiparticulate pulsatile drug delivery system for treating nocturnal asthma. Drug Deliv 2010;17:343-51.

104. Liu F, Moreno P, Basit AW. A novel double-coating approach for improved pHtriggered delivery to the ileo-colonic region of the gastrointestinal tract. Eur $\mathbf{J}$ Pharm Biopharm 2010;74:311-15.

105. Varum FJO, Veiga F, Sousa JS, Basit AW. Mucoadhesive platforms for targeted delivery to the colon. Int J Pharm 2011;420:11-19.

106. Rudolph MW, Klein S, Beckert TE, et al. A new 5-aminosalicylic acid multi-unit dosage form for the therapy of ulcerative colitis. Eur J Pharm Biopharm 2001;51:183-90. 
107. Gupta VK, Assmus MW, Beckert TE, Price JC. A novel pH- and time-based multi-unit potential colonic drug delivery system. II. Optimization of multiple response variables. Int J Pharm 2001;213:93-102.

108. Gupta VK, Beckert TE, Price JC. A novel pH- and time-based multi-unit potential colonic drug delivery system. I. Development. Int J Pharm 2001;213:83-91.

109. Bott C, Rudolph MW, Schneider ARJ, et al. In vivo evaluation of a novel pH- and time-based multiunit colonic drug delivery system. Aliment Pharmacol Ther 2004;20:347-53.

110. Patel NV, Patel JK, Shah SH, Patel JN. Central composite design for the formulation and optimization of a multi-unit potential colonic drug delivery system of budesonide for ulcerative colitis. Pharmazie 2011;66:124-29.

111. Kulthe SS, Bahekar JK, Godhani CC, et al. Modulated release of 5-fluorouracil from $\mathrm{pH}$-sensitive and colon targeted pellets: An industrially feasible approach. Drug Dev Ind Pharm 2013;39:138-45.

112. Gao C, Huang J, Jiao Y, et al. In vitro release and in vivo absorption in beagle dogs of meloxicam from Eudragit@ FS 30 D-coated pellets. Int J Pharm 2006;322:104-12.

113. Ferrari PC, Souza FM, Giorgetti L, et al. Development and in vitro evaluation of coated pellets containing chitosan to potential colonic drug delivery. Carbohyd Polym 2013;91:244-52.

114. Marvola M, Nykänen $\mathrm{P}$, Rautio S, et al. Enteric polymers as binders and coating materials in multiple-unit site-specific drug delivery systems. Eur J Pharm Sci 1999;7:259-67. 
115. Nykänen P, Krogars K, Säkkinen M, et al. Organic acids as excipients in matrix granules for colon-specific drug delivery. Int J Pharm 1999;184:251-61.

116. Leopold CS, Eikeler D. Basic coating polymers for the colon-specific drug delivery in inflammatory bowel disease. Drug Dev Ind Pharm 2000;26:1239-46.

117. Varshosaz J, Emami J, Tavakoli N, et al. Colon specific delivery of budesonide based on triple coated pellets: In vitro/in vivo evaluation. Acta Pharm 2012;62:341-56

118. Maroni A, Zema L, Loreti G, et al. Film coatings for oral pulsatile release. Int $\mathbf{J}$ Pharm 2013;457:362-71.

119. Maroni A, Del Curto MD, Zema L, et al. Film coatings for oral colon delivery. Int J Pharm 2013;457:372-94.

120. Ueda S, Hata T, Asakura S, et al. Development of a novel drug release system, time-controlled explosion system (TES): I - Concept and design. J Drug Target $1994 ; 2: 35-44$.

121. Ueda S, Yamaguchi H, Kotani M, et al. Development of a novel drug release system, time-controlled explosion system (TES). II. Design of multiparticulate TES and in vitro drug release properties. Chem Pharm Bull 1994;42:359-63.

122. Ueda S, Ibuki R, Kimura S, et al. Development of a novel drug release system, time-controlled explosion system (TES). III. Relation between lag time and membrane thickness. Chem Pharm Bull 1994;42:364-67.

123. Ueda S, Ibuki R, Kawamura A, et al. Development of a novel drug delivery system, time-controlled explosion system (TES): IV. In vivo drug release behavior. J Drug Target 1994;2:133-40. 
124. Hata T, Shimazaki Y, Kagayama A, et al. Development of a novel drug release system, time-controlled explosion system (TES). V. Animal pharmacodynamic study and human bioavailability study. Int J Pharm 1994;110:1-7.

125. Murata S, Ueda S, Shimojo F, et al. In vivo performance of time-controlled explosion system (TES) in GI physiology regulated dogs. Int J Pharm 1998;16:161-68.

126. Mohamad A, Dashevsky A. Development of pulsatile multiparticulate drug delivery system coated with aqueous dispersion Aquacoat ${ }^{\circledR}$ ECD. Int J Pharm 2006;318:124-31.

127. Mohamad A, Dashevsky A. In vitro and in vivo performance of a multiparticulate pulsatile drug delivery system. Drug Dev Ind Pharm 2007;33:113-19.

128. Liu Y, Liu S, Dai Q. Design and evaluation of $\mathrm{pH}$-independent pulsatile release pellets containing isosorbide-5-mononitrate. Chem Pharm Bull 2009;57:55-60.

129. Yadav D, Survase S, Kumar N. Dual coating of swellable and rupturable polymers on Glipizide loaded MCC pellets for pulsatile delivery: Formulation design and in vitro evaluation. Int J Pharm 2011;419:121-30.

130. Schultz P, Kleinebudde P. A new multiparticulate delayed release system. Part I: dissolution properties and release mechanism. J Control Release 1997;47:181-89.

131. Schultz P, Tho I, Kleinebudde P. A new multiparticulate delayed release system. Part II: coating formulation and properties of free films. J Control Release 1997;47:191-99.

132. Maroni A, Del Curto MD, Cerea M, et al. Polymeric coatings for a multiple-unit pulsatile delivery system: Preliminary study on free and applied films. Int J Pharm 
2013;440:256-63.

133. Del Curto MD, Palugan L, Foppoli A, et al. Erodible time-dependent colon delivery systems with improved efficiency in delaying the onset of drug release. J Pharm Sci 2014;103:3585-3593.

134. Caramella C, Colombo P, Conte U, et al. The role of swelling in the disintegration process. Int J Pharm Tech Prod Manuf 1984;5:1-5.

135. Giordano F, Rossi A, Bettini R, et al. Thermal behavior of paracetamol polymeric excipients mixtures. J Therm Anal Calorim 2002;68:575-590.

136. Maroni A, Del Curto MD, Serratoni M, et al. Feasibility, stability and release performance of a time-dependent insulin delivery system intended for oral colon release. Eur J Pharm Biopharm 2009;72:246-51.

137. Del Curto MD, Maroni A, Foppoli A, et al. Preparation and evaluation of an oral delivery system for time-dependent colon release of insulin and selected protease inhibitor and absorption enhancer compounds. J Pharm Sci 2009;98:4661-69.

138. Del Curto MD, Maroni A, Palugan L, et al. Oral delivery system for two-pulse colonic release of protein drugs and protease inhibitor/absorption enhancer compounds. J Pharm Sci 2011;100:3251-59.

139. Narisawa S, Nagata M, Danyoshi C, et al. An organic acid-induced sigmoidal release system for oral controlled-release preparations. Pharm Res 1994;11:11116.

140. Narisawa, S, Nagata M, Ito T, et al. Drug release behavior in gastrointestinal tract of beagle dogs from multiple unit type rate-controlled or time-controlled release 
preparations coated with insoluble polymer-based film. J Control Release $1995 ; 33: 253-60$.

141. Narisawa S, Nagata M, Hirakawa Y, et al. An organic acid-induced sigmoidal release system for oral controlled- release preparations. 2. Permeability enhancement of Eudragit RS coating led by the physicochemical interactions with organic acid. J Pharm Sci 1996;85:184-88.

142. Kao CC, Chen SC, Sheu MT. Lag time method to delay drug release to various sites in the gastrointestinal tract. J Control Release 1997;44:263-70.

143. Abrahamsson B, Alpsten M, Jonsson UE, et al. Gastro-intestinal transit of a multiple-unit formulation (metoprolol CR/ZOK) and a non-disintegrating tablet with the emphasis on colon. Int J Pharm 1996;140:229-35.

144. Schiller C, Fröhlich CP, Giessmann T, et al. Intestinal fluid volumes and transit of dosage forms as assessed by magnetic resonance imaging. Aliment Pharmacol Ther 2005;22:971-79.

145. Varum FJO, Merchant HA, Basit AW. Oral modified-release formulations in motion: The relationship between gastrointestinal transit and drug absorption. Int J Pharm 2010;395:26-36. 


\section{Figure Captions}

Figure 1. Outline of film formation by spray coating (nebulization of solutions/suspensions) or by melt coating (nebulization of molten materials).

Figure 2. Outline of film formation by dry powder coating (without liquids) or by liquid-assisted powder coating (with liquid plasticizers or binders nebulized). (Adapted with permission from [9])

Figure 3. Fluid bed coaters: A, top-spray; B, bottom-spray; C, tangential-spray. (Courtesy of Glatt GmbH)

Figure 4. Non-perforated coating pan for pellet processing. (Courtesy of IMA SpA) 
Table 1. Pellets with enzymatically degradable coatings: formulation and processing details

\begin{tabular}{|c|c|c|c|c|c|c|c|c|}
\hline & Reference & Pelletization technique & Pellet size & Active ingredient & Pelletization equipment & Functional excipients & $\begin{array}{l}\text { Coating level } \\
\text { (best proposed) }\end{array}$ & Coating equipment \\
\hline$[45,46]$ & $\begin{array}{l}\text { Ahmed IS et al 2005, } \\
2011\end{array}$ & Extrusion/spheronization & $1000-2000 \mu \mathrm{m}$ & $\begin{array}{l}\text { 5-ASA or } \\
\text { paracetamol }\end{array}$ & $\begin{array}{l}\text { Radial screen extruder and } \\
\text { spheronizer }\end{array}$ & $\begin{array}{l}\text { Pectin and EC (different } \\
\text { ratios) }\end{array}$ & $12-55 \%$ w.g. & Fluid bed coater \\
\hline [47-49] & $\begin{array}{l}\text { Fan LF et al } 2008, \mathrm{He} \\
\text { W et al } 2008\end{array}$ & Extrusion/spheronization & $800-1000 \mu \mathrm{m}$ & $5-\mathrm{FU}$ & $\begin{array}{l}\text { Spherical pellet granulator } \\
\text { or extruder and spheronizer }\end{array}$ & $\begin{array}{l}\text { Pectin and EC (1:2.5 or } \\
1: 3.5 \mathrm{w} / \mathrm{w})\end{array}$ & $18-22 \%$ w.g. & Fluid bed coater \\
\hline [50] & Bose A et al 2014 & Extrusion/spheronization & $710-1000 \mu \mathrm{m}$ & $5-\mathrm{FU}$ & Sieve extruder and spheronizer & Pectin and EC ( $3: 8$ w/w $)$ & - & - \\
\hline [51] & Semdé R et al 2000 & Extrusion/spheronization & $960-1400 \mu \mathrm{m}$ & Theophylline & - & $\begin{array}{l}\text { Pectin HM or calcium } \\
\text { pectinate and EC, Eudragit } \\
\text { NE or Eudragit RS }\end{array}$ & $19 \%$ w.g. & $\begin{array}{l}\text { Fluid bed coater } \\
\text { (Bottom-spray) }\end{array}$ \\
\hline [52] & Semdé R et al 2000 & Extrusion/spheronization & $960-1400 \mu \mathrm{m}$ & Theophylline & - & $\begin{array}{l}\text { Pectin HM/Eudragit RL } \\
\text { polyelectrolyte complexes } \\
\text { and Eudragit NE }\end{array}$ & $20 \%$ w.g. & $\begin{array}{l}\text { Fluid bed coater } \\
\text { (Bottom-spray) }\end{array}$ \\
\hline [54] & Ghaffari A et al 2008 & Extrusion/spheronization & $710-840 \mu \mathrm{m}$ & Theophylline & Extruder and spheronizer & $\begin{array}{l}\text { Pectin, chitosan and } \\
\text { Eudragit RS }\end{array}$ & $20 \%$ w.g. & $\begin{array}{l}\text { Fluid bed coater } \\
\text { (Bottom-spray) }\end{array}$ \\
\hline$[55,56]$ & $\begin{array}{l}\text { Hiorth M et al. 2006, } \\
2010\end{array}$ & Extrusion/spheronization & $700-1700 \mu \mathrm{m}$ & Riboflavin & $\begin{array}{l}\text { Radial screen extruder and } \\
\text { spheronizer }\end{array}$ & $\begin{array}{l}\text { Pectin } \mathrm{HM} \text { or alginate and } \\
\text { chitosan }\end{array}$ & - & Immersion coating \\
\hline [57] & Cui F et al 2007 & Extrusion/spheronization & $800-1200 \mu \mathrm{m}$ & 5-ASA & Extruder and spheronizer & $\begin{array}{l}\text { Calcium pectinate in cores; } \\
\text { inner coating pectin and } \\
\text { high-viscosity HPMC ( } 4: 1 \\
\text { w/w); intermediate coating } \\
\text { EC; outer coating Eudragit } \\
\text { L }\end{array}$ & $\begin{array}{l}\text { Inner coating } 12 \% \\
\text { w.g.; intermediate } \\
\text { coating } 10 \% \text { w.g.; } \\
\text { outer coating } 30 \%\end{array}$ & $\begin{array}{l}\text { Fluid bed coater } \\
\text { (Bottom-spray) }\end{array}$ \\
\hline [58] & $\begin{array}{l}\text { Sureshkumar R et al } \\
2009\end{array}$ & Extrusion/spheronization & $1185 \mu \mathrm{m}$ & Curcumin & $\begin{array}{l}\text { Roller extruder and } \\
\text { spheronizer }\end{array}$ & $\begin{array}{l}\text { Pectin and hgh-viscosity } \\
\text { HPMC }(1: 3 \mathrm{w} / \mathrm{w})\end{array}$ & - & Coating pan \\
\hline [60] & Shimono N et al 2003 & Powder layering & $1062 \pm 31 \mu \mathrm{m}$ & Paracetamol & $\begin{array}{l}\text { Centrifugal fluidizing } \\
\text { granulator }\end{array}$ & $\begin{array}{l}\text { Inner coating chitosan and } \\
\text { Eudragit RS }(2: 1 \mathrm{w} / \mathrm{w}) \text {; } \\
\text { outer coating Eudragit } \mathrm{L}\end{array}$ & $\begin{array}{l}\text { Inner coating } 138 \\
\mu \mathrm{m}\end{array}$ & $\begin{array}{l}\text { Centrifugal fluidizing } \\
\text { granulator }\end{array}$ \\
\hline [61] & $\begin{array}{l}\text { Kaur K and Kim K } \\
2009\end{array}$ & Suspension layering & $840-1000 \mu \mathrm{m}$ & Prednisolone & Fluid bed coater & $\begin{array}{l}\text { Inner coating Eudragit RS } \\
\text { and Eudragit RL ( } 4: 1 \\
\text { w/w); intermediate coating } \\
\text { chitosan, organic acid, } \\
\text { Eudragit RS and Eudragit } \\
\text { RL; outer coating Eudragit } \\
\text { L100 }\end{array}$ & $\begin{array}{l}\text { inner coating } 10 \% \\
\text { w.g.; intermediate } \\
\text { coating } 20 \% \text { w.g.; } \\
\text { outer coating } 20 \% \\
\text { w.g. }\end{array}$ & Fluid bed coater \\
\hline [62] & He W et al 2010 & Extrusion/spheronization & $800-1000 \mu \mathrm{m}$ & 5-ASA & - & $\begin{array}{l}\text { Chitosan and PVA (1:2-1:4 } \\
\mathrm{w} / \mathrm{w})\end{array}$ & $15 \%$ and $25 \%$ w.g. & Fluid bed coater \\
\hline
\end{tabular}




$$
\begin{array}{ll}
710-850 \mu \mathrm{m} & \text { Indomethacin or } \\
\text { (starting seeds) } & 5-\mathrm{FU}
\end{array}
$$

[69-75] Milojevic S et al 1996, Cummings JH et al 1996, Siew LF et al 2000, McConnell EL et al 2008, Basit AW et al 2009

[77-80] Freire $\mathrm{C}$ et al 2009 2010

[84-87] Karrout $Y$ et al 2009, 2010, 2011

Extrusion/spheronization 700-1000 $\mu \mathrm{m} \quad$ 5-ASA or (starting seeds) theophylline$$
\text { pancreatitis) }
$$

[93,94] Tozaki H et al 1999, Powder layering 2001

1000-1200 um Budesonide, insulin or (Asu
Twin screw extruder an

spheronizer

$$
\text { w/w) }
$$

Single screw extruder and Sodium alginate and spheronizer

chitosan $(95: 5 \mathrm{w} / \mathrm{w})$ 1,7)calcitonin

Amylose and EC (1:1-1:4

\section{Fluid bed coater}

Inner coating guar gum; outer coating Eudragit FS

Radial screen extruder and spheronizer

\section{Radial screen extruder and} spheronizer

Cylinder extruder and spheronizer or fluid bed coater (bottom-spray)

\section{Single screw extruder and} spheronizer

Inner coating xanthan gum; intermediate coating

Eudragit NE and Eudragit $\mathrm{L}(7: 3 \mathrm{w} / \mathrm{w})$; outer coating Eudragit FS $\mathrm{w} / \mathrm{w})$

High amylose starch (Hylon VII) and EC (1:2 w/w)

Starch or starch derivatives $\quad 15-20 \%$ w.g.

(Nutriose FB, Nutriose

$100 \%$ fibers, Eurylon 6

HP-PG or peas starch) and EC (1:2-1:5 w/w)

Starch acetate

Inner coating $44 \% \quad$ Fluid bed coater or $580 \%$ w.g.; outer (Bottom-spray) coating $30 \%$ w.g.

coating $12 \%$

.g.; intermediate oating $30 \%$ w.g. outer coating $25 \%$ w.g.

Fluid bed coater (Topspray)

Fluid bed coater $-20 \%$ w.g.

Fluid bed coater (Bottom-spray)

Fluid bed coater (Bottom-spray)

Fluid bed coater (Bottom-spray)

Manual dipping

Azoaromatic polymer

$10-20 \mu \mathrm{m}$

Coating pan

Segmented azoaromatic polyurethanes

10-20 um

Segmented azoaromatic polyurethanes

\section{Coating pan}


Table 2. Pellets with $\mathrm{pH}$-sensitive coatings: formulation and processing details

\begin{tabular}{|c|c|c|c|c|c|c|c|c|}
\hline & Reference & Pelletization technique & Pellet size & $\begin{array}{l}\text { Active } \\
\text { ingredient }\end{array}$ & Pelletization equipment & Functional excipients & $\begin{array}{l}\text { Coating level } \\
\text { (best proposed) }\end{array}$ & Coating equipment \\
\hline [96] & $\begin{array}{l}\text { Klokkers-Bethke K } \\
\text { and Fischer W } 1991\end{array}$ & Suspension layering & - & $\begin{array}{l}\text { Diltiazem } \\
\text { hydrochloride }\end{array}$ & $\begin{array}{l}\text { Fluid bed coater or coating } \\
\text { pan }\end{array}$ & $\begin{array}{l}\text { Inner coating Eudragit } S ; \\
\text { intermediate coating } \\
\text { succinic acid; outer coating } \\
\text { EC }\end{array}$ & - & $\begin{array}{l}\text { Fluid bed coater or } \\
\text { coating pan }\end{array}$ \\
\hline [97] & Tuleu C et al 2001 & Extrusion/spheronization & $710-1000 \mu \mathrm{m}$ & Sodium butyrate & - & $\begin{array}{l}\text { Eudragit } L \text { and Eudragit } S \\
(1: 1 \mathrm{w} / \mathrm{w})\end{array}$ & $60 \mathrm{mg} / \mathrm{cm}^{2}$ & $\begin{array}{l}\text { Fluid bed coater } \\
\text { (Bottom-spray) }\end{array}$ \\
\hline$[98,99]$ & $\begin{array}{l}\text { Akhgari A et al 2005, } \\
2006\end{array}$ & Suspension layering & $\begin{array}{l}850-1180 \mu \mathrm{m} \\
\text { (starting seeds) }\end{array}$ & Indomethacin & $\begin{array}{l}\text { Fluid bed coater } \\
\text { (Bottom-spray) }\end{array}$ & $\begin{array}{l}\text { Eudragit } S \text { and Eudragit } L \\
(80: 20) \text { or Eudragit RS, } \\
\text { Eudragit } S \text { and Eudragit L } \\
(20: 64: 16)\end{array}$ & $\begin{array}{l}20 \% \text { w.g. (Eudragit } \\
\text { S/Eudragit L } \\
\text { coating) or } 10 \% \\
\text { w.g. (Eudragit } \\
\text { RS/Eudragit } \\
\text { S/Eudragit L } \\
\text { coating) }\end{array}$ & $\begin{array}{l}\text { Fluid bed coater } \\
\text { (Bottom-spray) }\end{array}$ \\
\hline [100] & Chuong M et al 2009 & Extrusion/spheronization & $<12$ mesh & 5-ASA & $\begin{array}{l}\text { Radial screen extruder and } \\
\text { spheronizer }\end{array}$ & Eudragit $S$ & $30 \%$ w.g. & $\begin{array}{l}\text { Fluid bed coater } \\
\text { (Bottom-spray) }\end{array}$ \\
\hline [101] & Nguyen C et al 2012 & Extrusion/spheronization & $1190-2360 \mu \mathrm{m}$ & 5-ASA & $\begin{array}{l}\text { Radial screen extruder and } \\
\text { spheronizer }\end{array}$ & Eudragit S & $25 \%$ w.g. & $\begin{array}{l}\text { Fluid bed coater } \\
\text { (Bottom-spray) }\end{array}$ \\
\hline [102] & Xu M et al 2014 & Extrusion/spheronization & $600-800 \mu \mathrm{m}$ & 5-ASA & $\begin{array}{l}\text { Single screw extruder and } \\
\text { spheronizer }\end{array}$ & $\begin{array}{l}\text { Inner coating EC; outer } \\
\text { coating Eudragit } S\end{array}$ & $\begin{array}{l}\text { Inner coating } 18 \% \\
\text { w.g.; outer coating } \\
28 \% \text { w.g. }\end{array}$ & $\begin{array}{l}\text { Fluid bed coater } \\
\text { (Bottom-spray) }\end{array}$ \\
\hline [103] & $\begin{array}{l}\text { Kadam VD and } \\
\text { Gattani SG } 2010\end{array}$ & Suspension layering & $\begin{array}{l}\text { 150-300 mesh } \\
\text { (starting seeds) }\end{array}$ & Theophylline & $\begin{array}{l}\text { Fluid bed coater (Bottom- } \\
\text { spray) }\end{array}$ & $\begin{array}{l}\text { Eudragit } S \text { and Eudragit } \\
\text { RL (ratio } 1: 4 \mathrm{w} / \mathrm{w})\end{array}$ & $12 \%$ w.g. & $\begin{array}{l}\text { Fluid bed coater } \\
\text { (Bottom-spray) }\end{array}$ \\
\hline [105] & $\begin{array}{l}\text { Varum FJO et al } \\
2011\end{array}$ & Extrusion/spheronization & $1000-1400 \mu \mathrm{m}$ & Prednisolone & $\begin{array}{l}\text { Ram extruder and } \\
\text { spheronizer }\end{array}$ & $\begin{array}{l}\text { Inner coating partially } \\
\text { neutralized Eudragit; outer } \\
\text { coating Eudragit S }\end{array}$ & $\begin{array}{l}\text { Inner coating } 5 \\
\mathrm{mg} / \mathrm{cm}^{2} ; \text { outer } \\
\text { coating } 5 \mathrm{mg} / \mathrm{cm}^{2}\end{array}$ & $\begin{array}{l}\text { Fluid bed coater } \\
\text { (Bottom-spray) }\end{array}$ \\
\hline [106] & $\begin{array}{l}\text { Rudolph MW et al } \\
2001\end{array}$ & Extrusion/spheronization & $800-1250 \mu \mathrm{m}$ & 5-ASA & $\begin{array}{l}\text { Hollow cylinder extruder } \\
\text { and spheronizer }\end{array}$ & Eudragit FS & $55 \mu \mathrm{m}$ & $\begin{array}{l}\text { Fluid bed coater (Top- } \\
\text { spray) }\end{array}$ \\
\hline$[107,108]$ & Gupta VK et al 2001 & Powder layering & $800-1000 \mu \mathrm{m}$ & 5-ASA & Coating pan & $\begin{array}{l}\text { Inner coating Eudragit RL } \\
\text { and Eudragit RS }(1: 4) \text {; } \\
\text { outer coating Eudragit FS }\end{array}$ & $\begin{array}{l}\text { Inner coating } 2-8 \% \\
\text { w.g.; outer coating } \\
20 \% \text { w.g. }\end{array}$ & $\begin{array}{l}\text { Fluid bed coater } \\
\text { (Top-spray) }\end{array}$ \\
\hline [109] & Bott C et al 2004 & Extrusion/spheronization & $800-1250 \mu \mathrm{m}$ & Caffeine & $\begin{array}{l}\text { Hollow cylinder extruder } \\
\text { and spheronizer }\end{array}$ & $\begin{array}{l}\text { Inner coating Eudragit RL } \\
\text { and Eudragit RS; outer } \\
\text { coating Eudragit FS }\end{array}$ & - & Fluid bed coater \\
\hline
\end{tabular}




\begin{tabular}{|c|c|c|c|c|c|c|c|c|}
\hline [110] & Patel NV et al 2011 & Powder layering & $800-1000 \mu \mathrm{m}$ & Budesonide & Coating pan & $\begin{array}{l}\text { Inner coating Eudragit RL } \\
\text { and Eudragit RS; outer } \\
\text { coating Eudragit FS }\end{array}$ & $\begin{array}{l}\text { Inner coating } 2-8 \% \\
\text { w.g.; outer coating } \\
10-30 \% \text { w.g. }\end{array}$ & Fluid bed coater \\
\hline [111] & Kulthe SS et al 2013 & Extrusion/spheronization & $875 \pm 80 \mu \mathrm{m}$ & $5-\mathrm{FU}$ & $\begin{array}{l}\text { Radial screen extruder and } \\
\text { spheronizer }\end{array}$ & $\begin{array}{l}\text { Inner coating Eudragit NE; } \\
\text { outer coating Eudragit FS }\end{array}$ & $\begin{array}{l}\text { Inner coating } 15 \% \\
\text { w.g.; outer coating } \\
15 \% \text { w.g. }\end{array}$ & $\begin{array}{l}\text { Fluid bed coater } \\
\text { (Bottom-spray) }\end{array}$ \\
\hline [112] & Gao C et al 2006 & Solution layering & $\begin{array}{l}710-850 \mu \mathrm{m} \\
\text { (starting seeds) }\end{array}$ & Meloxicam & Fluid bed coater & $\begin{array}{l}\text { Inner coating HPMC; outer } \\
\text { coating Eudragit FS }\end{array}$ & $15 \%$ w.g. & Fluid bed coater \\
\hline [113] & Ferrari PC et al 2013 & Extrusion/spheronization & $962 \pm 193 \mu \mathrm{m}$ & Metronidazole & $\begin{array}{l}\text { Radial screen extruder and } \\
\text { spheronizer }\end{array}$ & $\begin{array}{l}\text { Inner coating Kollicoat SR; } \\
\text { outer coating Kollicoat } \\
\text { MAE }\end{array}$ & - & Fluid bed coater \\
\hline$[114,115]$ & $\begin{array}{l}\text { Marvola M et al } \\
1999, \text { Nykänen P et } \\
\text { al } 1999\end{array}$ & Sieve granulation & $1000-1700 \mu \mathrm{m}$ & $\begin{array}{l}\text { Ibuprofen or } \\
\text { furosemide }\end{array}$ & Sieve granulator & $\begin{array}{l}\text { Eudragit S, Eudragit L or } \\
\text { HPMCAS and organic } \\
\text { acids (optional) in cores; } \\
\text { coating HPMCAS or CAP }\end{array}$ & $20 \%$ w.g. & $\begin{array}{l}\text { Fluid bed coater } \\
\text { (Bottom-spray) }\end{array}$ \\
\hline$[24,116]$ & $\begin{array}{l}\text { Leopold CS and } \\
\text { Eikeler D 1998, } 2000\end{array}$ & Tableting & $\begin{array}{l}\text { minitablets } 3 \\
\text { mm diameter, } \\
2.5 \mathrm{~mm} \text { height }\end{array}$ & Dexamethasone & Single-punch press & $\begin{array}{l}\text { Carbopol } 934 \text { in cores } \\
\text { (optional); inner coating } \\
\text { Eudragit E; intermediate } \\
\text { coating HPC; outer coating } \\
\text { HPMCAS }\end{array}$ & $\begin{array}{l}\text { Inner coating 140- } \\
350 \mu \mathrm{m} \text {; } \\
\text { intermediate } \\
\text { coating } 30 \mu \mathrm{m} ; \\
\text { outer coating } 35 \mu \mathrm{m}\end{array}$ & Coating pan \\
\hline [117] & $\begin{array}{l}\text { Varshosaz J et al } \\
2012\end{array}$ & Extrusion/spheronization & $840-1000 \mu \mathrm{m}$ & Budesonide & $\begin{array}{l}\text { Radial screen extruder and } \\
\text { spheronizer }\end{array}$ & $\begin{array}{l}\text { Citric acid in cores; inner } \\
\text { coating HPMC; } \\
\text { intermediate coating } \\
\text { Eudragit; outer coating } \\
\text { Eudragit HPMCAS }\end{array}$ & $\begin{array}{l}\text { Inner coating } 6 \% \\
\text { w.g.; intermediate } \\
\text { coating } 30 \% \text { w.g.; } \\
\text { outer coating } 15 \% \\
\text { w.g. }\end{array}$ & $\begin{array}{l}\text { Fluid bed coater (Top- } \\
\text { spray) }\end{array}$ \\
\hline
\end{tabular}


Table 3. Pellets with time-dependent coatings: formulation and processing details

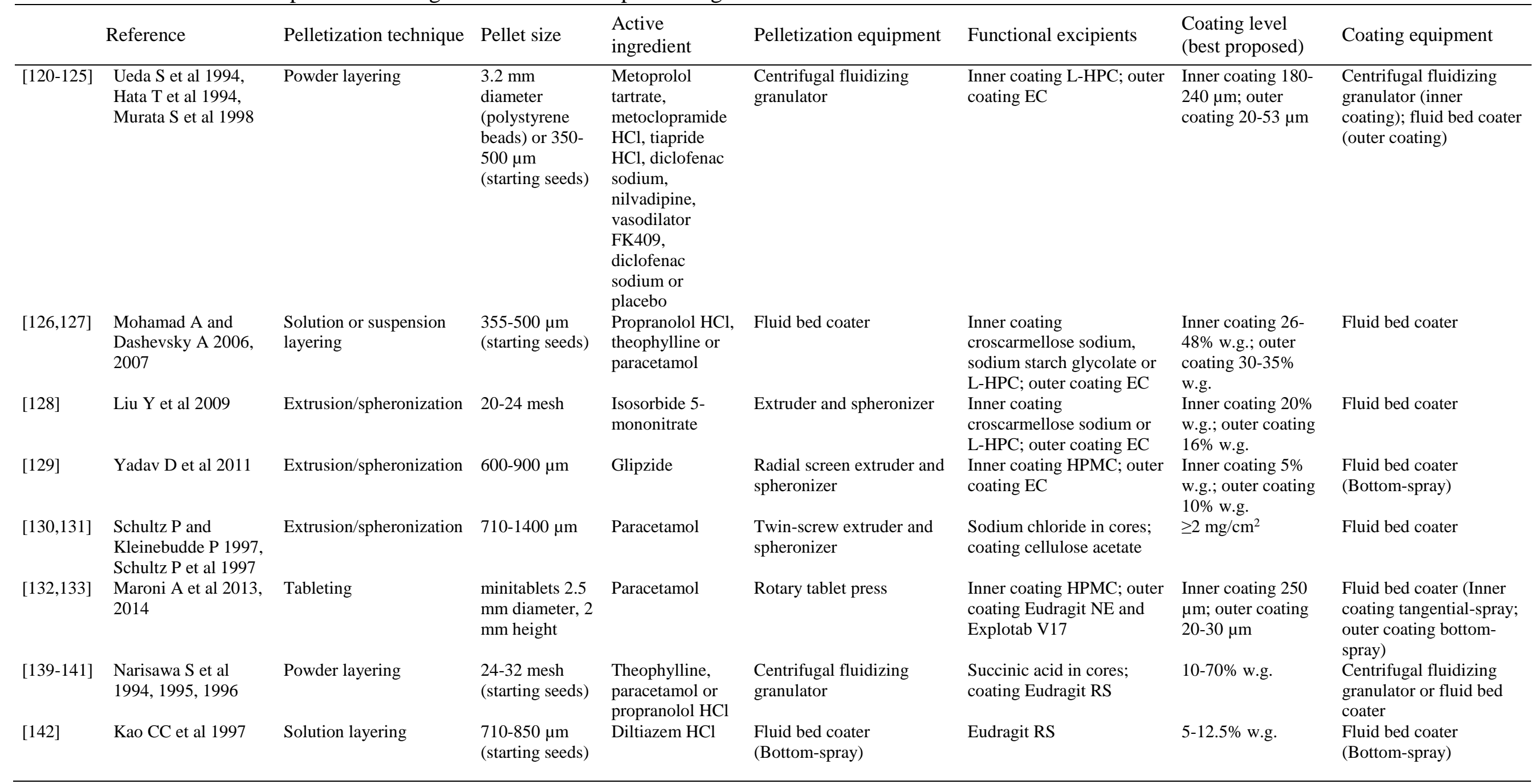


Figure 1. Outline of film formation by spray coating (nebulization of solutions/suspensions) or by melt coating (nebulization of molten materials).

○

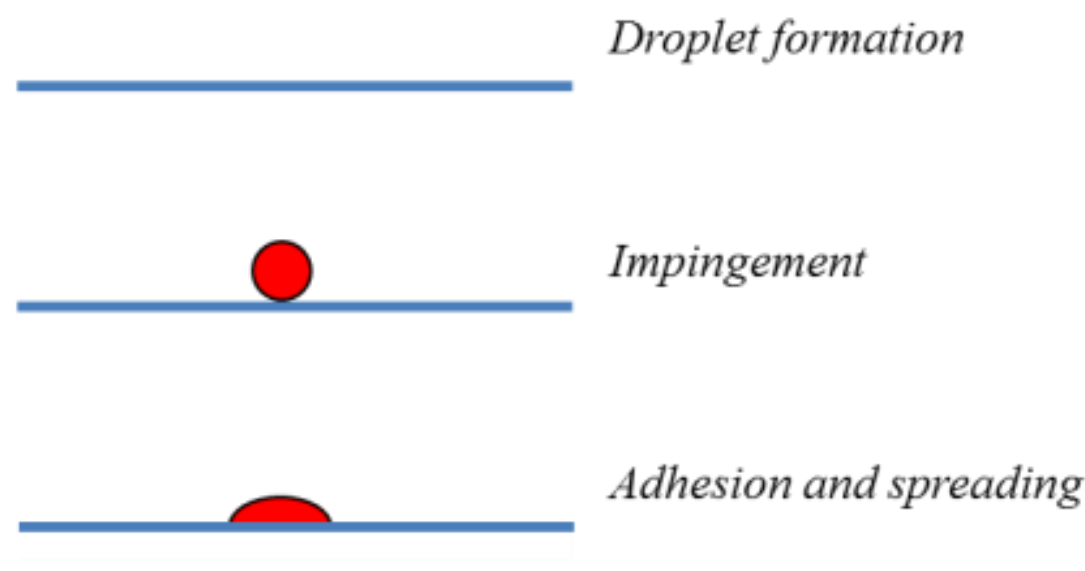

\section{Coalescence}

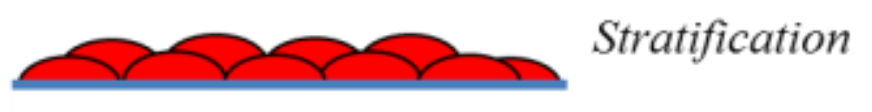

Solid film formation by evaporation (spray coating) or by cooling (melt coating) 
Figure 2. Outline of film formation by dry powder coating (without liquids) or by liquid-assisted powder coating (with liquid plasticizers or binders nebulized).

(Adapted with permission from [9])

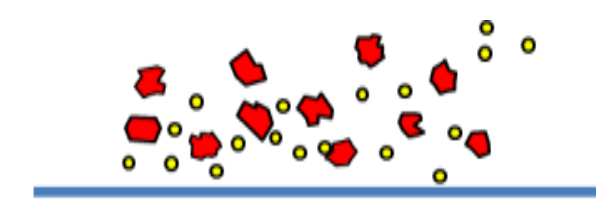

Powder dosing (optional liquid spray)

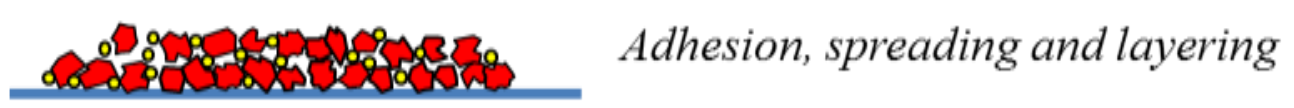

0000 Coalescence and sintering

Levelling

Solid film formation by cooling 
Figure 3. Fluid bed coaters: A, top-spray; B, bottom-spray; C, tangential-spray.

(Courtesy of Glatt GmbH)

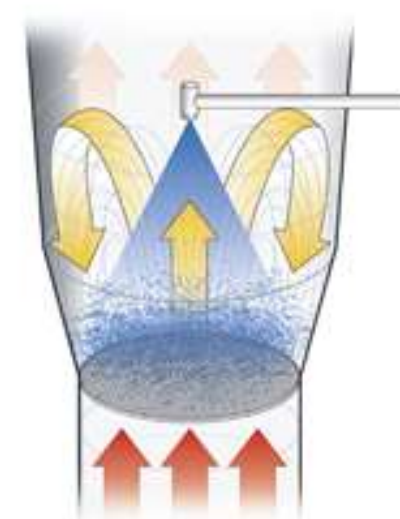

A

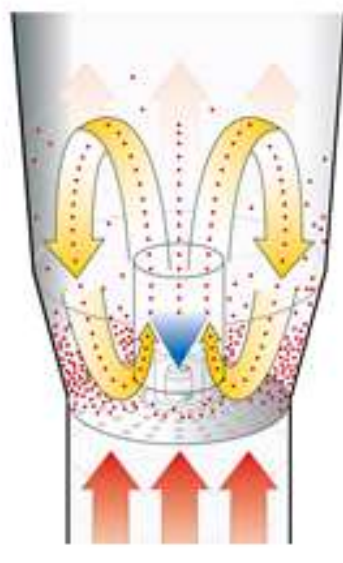

B

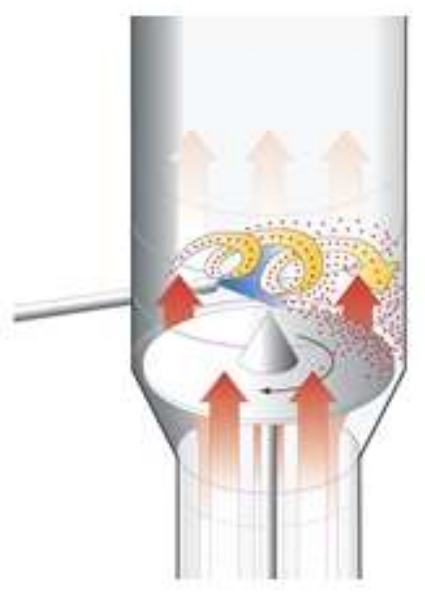

C 
Figure 4. Non-perforated coating pan for pellet processing.

(Courtesy of IMA SpA)

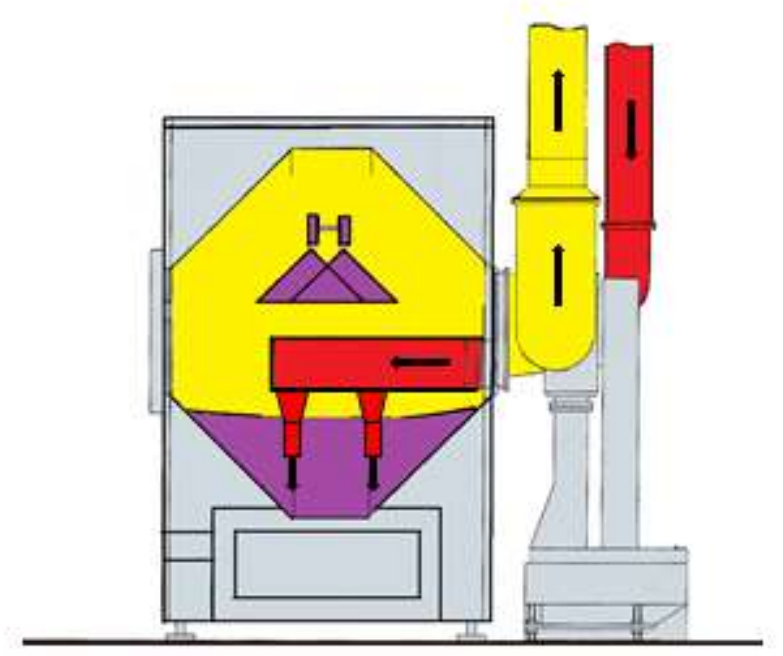

